\title{
Identification of Fanconi Anemia Pathway Genes as Novel Prognostic Biomarkers and Therapeutic Targets for Breast Cancer
}

\section{Hongsheng Lin}

First Affiliated Hospital, Guangxi University of Chinese Medicine

\section{Yangyi Xie}

GuangXi University of Chinese Medicine

\section{Aiping Pan}

First Affiliated Hospital, Guangxi University of Chinese Medicine

\section{Wei Wei}

First Affiliated Hospital, Guangxi University of Chinese Medicine

\section{Limei Diao}

First Affiliated Hospital, Guangxi University of Chinese Medicine

\section{Li Yang}

First Affiliated Hospital, Guangxi University Of Chinese Medicine

\section{Yinzhi Kong}

GuangXi University of Chinese Medicine

Mingfen Li ( $\square$ limf@gxtcmu.edu.cn )

First Affiliated Hospital, Guangxi University of Chinese Medicine https://orcid.org/0000-0003-38909490

\section{Primary research}

Keywords: Breast cancer, Biomarker, Fanconi anemia pathway, Prognosis, DNA repair

Posted Date: January 14th, 2021

DOl: https://doi.org/10.21203/rs.3.rs-143763/v1

License: (c) (i) This work is licensed under a Creative Commons Attribution 4.0 International License. Read Full License 


\section{Abstract}

\section{Background}

Globally, breast cancer is one of the most common cancers with poor prognosis. The Fanconi anemia (FA) pathway genes maintain genome stability and play important roles in human diseases, including cancer. However, the prognostic values and biological roles of FA pathway genes in breast cancer have not been clarified.

\section{Methods}

In this study, the ONCOMINE, UCSC Xena, UALCAN, Kaplan-Meier plotter, cBioPortal, GEPIA, GeneMANIA, DAVID and TIMER databases were used to investigate the transcriptional and survival data of FA pathway genes in patients with breast cancer.

\section{Results}

Most of the FA pathway genes were found to be significantly upregulated in breast cancer tissues when compared to normal tissues. Additionally, the elevated expression levels of FA pathway genes were significantly associated with poor survival outcomes in breast cancer patients. Through functional enrichment analysis, the FA pathway genes were positively associated with cell cycle and nucleoplasm and negatively correlated with SRP-dependent co-translational protein targeting to membrane and ribosome. Furthermore, the expression levels of FA pathway genes exhibited a significant positive association with immune infiltration.

\section{Conclusion}

The FA pathway genes are potential prognostic biomarkers for breast cancer and may offer effective as well as new strategies for cancer management.

\section{Background}

Breast cancer is the most common type of cancer among women. It accounts for $30 \%$ of all new cancer diagnoses, and is the second leading cause of cancer associated mortalities among women [1]. It is comprised of a heterogeneous group of diseases with different histopathological characteristics and high genetic variability, and is therefore, characterized by different prognostic outcomes. Specific breast cancer subtypes are defined by their histopathological appearance and expression of hormone receptors, including oestrogen receptor (ER), progesterone receptor (PR) and human epidermal growth factor receptor 2 (HER2) [2]. Among the genetic risk factors, pathogenic mutations in high and moderate-risk cancer predisposition genes such as BRCA1 and BRCA2, have an important impact on breast cancer development [3]. Due to tumor heterogeneity, the current breast cancer biomarkers for predicting prognosis have some limitations, therefore, there is a need to establish new biomarkers as prognostic indicators to effectively enhance prognosis and individualize breast cancer treatment. 
Fanconi anemia (FA) is a recessive autosomal or X-linked disease that was first described by the Swiss pediatrician, Guido Fanconi in 1927 [4]. It is diagnosed by the presentation of bone marrow failure at a median age of 7 years [5]. Fanconi anemia is a rare, cancer prone disease with mutations in at least 22 genes [6]. In addition, protein products of these 22 FA genes along with the FA-associated proteins, interact in a common cellular pathway, known as the FA pathway, to repair DNA interstrand cross-links (ICLs). The FA pathway plays a major role in responses to replication stress by facilitating the resolution of DNA lesions arising from DNA replication [7]. Moreover, amplification and gain-of-function mutations in FA genes is advantageous in cancer cells by alleviating replication stress and mitigating chemotherapeutics induced DNA damage [8]. Studies have documented the key functions of FA genes in different kinds of cancers, including prostate cancer [9], colorectal cancer [10], hepatocellular carcinoma [11], bladder cancer [12] and breast cancer [13]. Breast cancer susceptibility genes, BRCA1 and BRCA2, also known as FANCS and FANCD1, respectively, are involved in the FA pathway. Furthermore, some of the FA pathway genes are associated with clinicopathological features in breast cancer and could serve as cancer diagnostic or prognostic biomarkers [14]. However, studies regarding the expression patterns and prognostic values of all the FA pathway genes are few. Therefore, on the basis of the analysis of thousands of gene expressions or variations in copy numbers published online, this study explored expressions and mutations in FA pathway genes in patients with breast cancer to determine their expression patterns, distinct prognostic values, and potential function of these genes in breast cancer.

\section{Methods}

\section{ONCOMINE}

ONCOMINE (www.oncomine.org) is a cancer microarray database that allows genome-wide expression analysis [15]. In this study, the FA pathway gene transcriptional levels in different cancers were analyzed using ONCOMINE in this study. Datasets were screened with thresholds of $p$-value (1E-4), fold change (2) and gene rank (top 10\%).

\section{UCSC Xena}

UCSC Xena (http://xena.ucsc.edu) is a high-performance visualization and analysis tool for large public repositories such as The Cancer Genome Atlas (TCGA) and the Genomic Data Commons (GDC) as well as private datasets [16]. In this study, the UCSC Xena browser was used to determine the mRNA expression levels of the FA pathway genes in BRCA (GDC TCGA Breast Cancer, $n=1284$ ).

\section{UALCAN}

UALCAN (http://ualcan.path.uab.edu) is a web-portal used for performing in-depth analyses on TCGA transcriptomic data [17]. It was used to assess the mRNA expression levels of FA pathway genes in breast cancer tissues and in the corresponding normal tissues.

\section{Kaplan-Meier plotter}


The prognostic values of FA pathway genes in breast cancer were evaluated using the Kaplan-Meier Plotter (www.kmplot.com). This online platform can be used to assess the significance of the expression levels of various genes on clinical outcomes in cancer patients [18]. Furthermore, the platform was used to analyze the associations between the expression levels of FA pathway genes and clinicopathological features in breast cancer.

\section{cBioPortal}

The cBioPortal for Cancer Genomics (http://cbioportal.org) is a comprehensive web resource that can visualize and analyze multidimensional cancer genomic data [19]. Therefore, data from this platform was used to analyze changes in the frequency of FA pathway genes in breast cancer.

\section{GEPIA}

GEPIA (http://gepia.cancer-pku.cn/) is an interactive web application for gene expression analysis. It is based on 9736 tumor and 8587 normal tissue samples from the TCGA and the Genotype-Tissue Expression (GTEx) databases [20]. Thus, it was used to assess the correlations between the expression levels of FA pathway genes in breast cancer.

\section{GeneMANIA}

GeneMANIA (http://www.genemania.org) is a web interface for the identification of related genes from many large, publicly available biological datasets [21]. In this study, the relationship between FA pathway genes and their interactive genes was analyzed using this database.

\section{DAVID}

DAVID (http://david.abcc.ncifcrf.gov) is an annotation, visualization and integrated discovery database that is able to extract biological features associated with specific genes [22]. Gene Ontology (GO) and Kyoto Encyclopedia of Genes and Genomes (KEGG) pathway enrichment analysis of FA pathway genes and their closely associated genes in breast cancer were performed by DAVID and visualized using $R$ language.

\section{TIMER}

TIMER (cistrome.shinyapps.io/timer) is a web interface for comprehensive molecular characterization of tumor-immune interactions [23]. The expression level of FA pathway genes in breast cancer and their correlation with tumor purity and infiltrating immune cells such as B cells, CD8+ T cells, CD4+ T cells, macrophages, neutrophils and dendritic cells were assessed using TIMER.

\section{Results}

\section{mRNA expression levels of FA pathway genes in breast cancer}


Based on the ONCOMINE data, the transcriptional levels of various FA pathway genes were found to be elevated in various types of cancers, such as colorectal cancer, cervical cancer and breast cancer (Fig. 1). Moreover, in breast cancer, the transcriptional levels of FANCA, FANCB, UBE2T (FANCT), FANCD2, FANCl, BRCA2 (FANCD1), BRIP1 (FANCJ), RAD51 (FANCR), BRCA1 (FANCS), MAD2L2 (FANCV) and RFWD3 (FANCW) were significantly elevated, while the transcriptional levels of FANCC and XRCC2 (FANCU) were significantly suppressed in some specific datasets. Then, the expression levels of all the FA pathway genes in breast cancer were determined using the UCSC Xena browser. It was found that all the FA pathway genes were highly expressed in BRCA (Fig. 2). Notably, FANCI and RFWD3 (FANCW) exhibited the highest mRNA levels while FANCB had the lowest. We further compared the mRNA expression levels of FA pathway genes in breast cancer and their corresponding normal tissues. Results from the UALCAN database revealed that the genes were significantly upregulated in breast cancer compared to their corresponding normal tissues, except for FANCE and FANCM which were downregulated in tumors (Fig. $3)$.

\section{The prognostic value of FA pathway genes in breast cancer}

The Kaplan-Meier plotter was used to determine the potential prognostic value of FA pathway genes in breast cancer. About half of the genes that were highly expressed were shown to exhibit a significant positive correlation with worse recurrent free survival (RFS) of breast cancer patients (Fig. 4). These genes include; FANCB, FANCG, FANCL, UBE2T (FANCT), FANCI, BRIP1 (FANCJ), BRCC5 (FANCR), BRCA1 (FANCS), MAD2L2 (FANCV) and RFWD3 (FANCW). In contrast, elevated mRNA expression levels of FANCC, SLX4 (FANCP), PALB2 (FANCN), XRCC2 (FANCU) and ERCC4 (FANCQ) were associated with favorable RFS. The other genes did not exhibit a significant correlation with the RFS of breast cancer patients.

We further used the Kaplan-Meier plotter to investigate the correlations between the expression levels of FA pathway genes and patients' overall survival (OS), distant metastasis free survival (DMFS) and post progression survival (PPS). The result forest plots are presented in Fig. 5.

\section{Association between the prognostic value of FA pathway genes in breast cancer with different clinicopathological features}

The relationship between FA pathway genes and different clinicopathological features was investigated to elucidate on the roles of these genes in breast cancer prognosis. The clinicopathological features included cancer grade, ER status, PR status, HER2 status and TP53 status. It was revealed that elevated mRNA expression levels of $\mathrm{FANCl}$ were associated with poor RFS in grade 1 breast cancer. Additionally, elevated mRNA expression levels of FANCA, FANCE, FANCL, FANCI, BRCC5 and RFWD3 were correlated to worse RFS in grade 2 breast cancer. However, FANCF and PALB2 were associated with better RFS in grade 2 breast cancer. Moreover, low mRNA expression levels of FANCI and BRCA1 were associated with better RFS in grade 3 breast cancer, while BRIP1 and RAD51C were identified as good prognostic factors for grade 3 breast cancer. These results are presented in Table 1. 
Moreover, BRCA1 was found to be a promising marker for unfavorable prognosis in both ER positive and negative patients, while FANCA, FANCB, FANCE, FANCG, FANCL, UBE2T, FANCI, BRIP1, RAD51C, BRCC5 and RFWD3 were significantly associated with unfavorable RFS in ER positive patients. However, FANCC and FANCD1 were associated with favorable RFS in ER negative patients (Table 2).

Furthermore, elevated mRNA expression levels of FANCA, FANCG, UBE2T, FANCI, BRIP1, RAD51C, BRCC5 and BRCA1 were shown to contribute to unfavorable RFS in PR positive patients while elevated expression levels of SLX4 and ERCC4 were associated with shorter RFS in PR negative patients (Table 3).

Table 4 shows that PALB2 exhibited a significant association with unfavorable RFS in HER2 positive patients. However, FANCA, FANCB, FANCC, FANCG, UBE2T, SLX4, FANCI, BRIP1, RAD51C, BRCA1 and ERCC4 were associated with poor RFS while FANCF was associated with better RFS in HER2 negative patients. Nevertheless, FANCD2 was a good prognostic factor in both HER2 positive and negative patients.

Based on the TP53 status, elevated expression levels of UBE2T were strongly associated with worse RFS while FANCL, FAND2 and RAD51C were correlated with better RFS in TP53-mutated patients. In patients with wild type TP53, FANCA, FANCI, BRCA1 and RFWD3 were associated with unfavorable RFS (Table 5).

\section{Genetic alterations and interaction analysis of FA pathway genes in breast cancer}

We further performed a comprehensive analysis of the molecular characteristics of genes in the FA pathway. The frequency of genetic alterations in these genes among breast cancer patients was determined using the cBioPortal database. It was found that mRNA deregulation was one of the most important single factors for genetic alterations in different kinds of breast cancers (Fig. 6a). Mutation and amplification were the most common alterations in these samples. In addition, OncoPrint was used to show a visual summary of alterations in the FA pathway genes across a set of breast cancer samples (Fig. 6b). Moreover, expression correlations were determined using GEPIA to further define the relationships among the FA pathway genes. There was a low to high positive correlation among most FA pathway genes (Fig. 7a). Additionally, a network of FA pathway genes and their functionally related genes was constructed using GeneMANIA (Fig. 7b). Twenty genes were found to be closely associated with the regulatory functions of differentially expressed FA pathway genes. These genes were FAAP24, FAAP100, RAD51B, XRCC3, RAD52, BARD1, BLM, RMI1, TOP3A, ATR, FAN1, APITD1, TOPBP1, USP1, G2E3, RAD51D, RPA1, RPA2, ERCC1 and ATRIP.

\section{Functional enrichment analysis of FA-related genes in breast cancer}

We used UALCAN to isolate the top 50 genes that were positively and negatively correlated with individual genes of the FA pathway in breast cancer. This was done to explore the underlying mechanisms of FA pathway genes in cancer. In addition, DAVID was used to perform GO and KEGG pathway enrichment analysis of the FA-associated genes in breast cancer. Fig. 8 shows the most highly enriched GO items that were positively and negatively correlated with FA pathway genes in breast cancer. Among the 
positively correlated GO items, the most enriched biological process (BP) term was cell division, the most enriched cellular component (CC) term was nucleoplasm, and the most enriched molecular function (MF) term was protein binding (Fig. 8a). In the negatively correlated GO items, the FA-associated genes were shown to participate in various functions, especially SRP-dependent co-translational protein targeting to membrane as well as ribosome and structural constituent of ribosome (Fig. 8b). Moreover, KEGG pathway enrichment analysis revealed that the positively correlated pathways were mainly involved in cell cycle, oocyte meiosis and viral carcinogenesis (Fig. 8c). Besides, ribosomes, along with their metabolic pathways, were the most enriched pathways that were found to be negatively correlated with FA pathway genes in breast cancer (Fig. 8d).

\section{Correlation between immune infiltration and FA pathway genes in patients with breast cancer}

Given that inflammatory responses and infiltrating immune cells can affect breast cancer prognosis, we evaluated the association between differentially expressed FA pathway genes and immune cell infiltration using the TIMER database. It was found that the mRNA expression levels of FA pathway genes were positively associated with tumor purity, while FANCE, FANCM, BRCA2 (FANCD1) and MAD2L2 (FANCV) had no significant correlation with the tumor purity of patients with breast cancer (Fig. 9). Furthermore, most FA pathway genes were positively associated with immune infiltration levels of $B$ cells, CD8+ $T$ cells, CD4+ T cells, macrophages, neutrophils and dendritic cells, except for FANCE of macrophages, FANCF of dendritic cells, FANCG of macrophages, FANCL of macrophages, UBE2T of macrophages, RAD51C of CD4+ $T$ cells, MAD2L2 of CD8+ T cells and macrophages, which showed significant negative associations.

\section{Discussion}

Chemotherapy is one of the most important treatments for breast cancer after surgery. Approximately one-third of patients with breast cancer present metastases, which are the main cause of death in these patients [24]. Studies have documented that tumor responses to chemotherapeutic drugs is closely associated with the regulation of the DNA repair system [25]. Some tumor cells can resist DNA damage drugs by activating self-DNA repair mechanisms [26]. Moreover, deficiency in the proteins involved in DNA damage repair is considered a major determinant of the responses to chemotherapy in cancer cells [27]. Previous studies reported that the FA pathway, also referred to as the FA-BRCA pathway, can modulate tumor progression and immunotherapeutic effects [8]. However, the prognostic values and biological functions of FA pathway genes in breast cancer have not been well elucidated.

DNA repair involves multiple enzymes and genes. Inactivating mutations in DNA repair components are common and often lead to certain DNA repair deficiencies. Therefore, cancer cells become hyperdependent on the remaining repair pathways for survival and proliferation [28]. The FA pathway is a stepwise multiprotein complex pathway that confers cellular hypersensitivity to DNA intercalating substances, such as cisplatin, that trigger DNA ICLs [29]. FA pathway activation status may serve as a clinical biomarker for cancer patients at different treatment stages. Herein, the expression levels of FA 
pathway genes in breast cancer were determined before evaluating their association with survival outcomes in breast cancer patients. Expression levels of 20 genes were shown to be significantly higher in breast cancer tissues than in the corresponding normal tissues, except for FANCE and FANCM, which were downregulated in tumors. Moreover, elevated expression levels of FANCB, FANCG, FANCL, UBE2T, FANCI, BRIP1, BRCC5, BRCA1, MAD2L2 and RFWD3 in breast cancer were associated with worse RFS. However, elevated mRNA levels of FANCC, SLX4, PALB2, XRCC2 and ERCC4 were correlated with a favorable RFS. Furthermore, elevated expression levels of FANCA, FANCG, UBE2T, FANCI, FANCD1, BRCC5, BRCA1 and RFWD3 were associated with worse OS. These findings imply that FANCG, UBE2T, FANCI, BRCC5, BRCA1 and RFWD3 exhibited better prospects for utilization as prognostic biomarkers in breast cancer patients. Studies have documented that the prognosis of breast cancer patients is associated with tumor pathological tissue type, such as ER, PR and HER2 status, which have played a role in the identification of which patients are likely to benefit from endocrine therapy or targeted therapy [30]. TP53 is the most frequent mutational target in human cancers. Mutations in TP53 are associated with different types of malignancies and adverse prognoses, including during breast cancer [31]. In this study, most FA pathway genes showed a close relationship with worse RFS of breast cancer patients with different clinicopathological features including cancer grade, ER status, PR status, HER2 status and TP53 status. Collectively, the FA pathway genes were potential therapeutic targets and prognostic biomarkers for breast cancer.

Next-generation sequencing has uncovered the frequency of mutations and copy number alterations across different cancer types and demonstrated that alterations in DNA repair mechanisms are common events in carcinogenesis. Mutations with high variant allele frequencies (VAFs) indicated early appearance of tumorigenesis or tremendous contribution to the later expansion of tumor cells [32]. Moreover, compensatory mutations in BRCA1 and BRCA2 that restore homologous recombination (HR) functionality in initially cisplatin sensitive tumors is able to develop cisplatin resistance [33]. Comprehensively revealing mutation characteristics in breast cancer elucidates on the mutational diversity among different molecular subtypes, enables the identification of potential treatment biomarkers, and provides a basis for genomic targeting strategies and clinical trials [34]. Given the significant differential expression of genes in the FA pathway, we further explored their molecular characteristics. It was found that mutation, fusion, amplification, deep deletion and multiple alterations were the main mutational signatures of FA pathway genes in breast cancer. Notably, amplification was the main characteristic of gene mutations in the FA pathway genes, which meant that the FA pathway could be a significant compensatory DNA repair pathway for cancer cells. More importantly, these mutational signatures may be new therapeutic targets for precision medicine, providing opportunities for personalized treatment strategies based on the imperfection of patient's DNA repair networks.

Cell response to DNA damage is a complex mechanism involving multiple protein networks with interconnected functions that are responsible for damage detection, cell cycle regulation and DNA repair. Establishing the underlying mechanisms involved in the association between FA pathway and breast cancer, besides DNA damage repair, will have significant implications in clinical practice [35]. In this study, a low to high expression correlation among FA pathway genes in breast cancer was obtained, 
suggesting that they played a synergistic role in tumorigenesis and cancer progression. Then, we determined the core genes that were potentially associated with FA pathway gene functions. Some of them were identified as important gene regulators. For instance, studies have shown that FANCM and its binding partner, FAAP24, suppress the formation of DNA double-stranded breaks and mitotic recombination in a manner that is dependent on FANCM translocase activity [36]. Moreover, BRCA1BARD1 are required for fork protection and are associated with cancer development [37]. Functional enrichment analysis was then performed to elucidate on the biological functions of FA pathway genes in breast cancer. The FA-related genes were found to be primarily positively associated with the cell cycle and nucleoplasm. However, the FA pathway genes were also negatively correlated with genes involved in SRP-dependent cotranslational protein targeting to membrane and ribosome. The ribosome plays a critical role in normal cellular physiology, in cellular responses to internal and external environmental stimuli, and in the pathogenesis of human diseases [38]. Under stress situations, a decreased ribosomal activity and reduced protein synthesis are shown, subsequently leading to nuclear mobilization and DNA repair activation to minimize the negative impact to cell growth [39]. This may be the mechanism through which ribosome-related genes are down-regulated. Studies have begun to elucidate the interplay between ribosomal biogenesis, which means ribosomal synthesis and DNA repair [40]. $\mathrm{FANCl}$ is required for ribosomal biogenesis, and may function by coordinating rDNA replication and transcription [41]. Nonetheless, the exact functions of FA pathway genes in breast cancer should be investigated further.

The cancer immune microenvironment plays an important role in tumor progression [42]. In recent years, immunotherapy has been found to be a promising therapy for cancer, and the development of immunological biomarkers has been of increasing importance [43]. In this study, there was a significant positive correlation between the mRNA expressions of FA pathway genes and tumor purity in breast cancer. Tumor purity is highly associated with genomic patterns and immune phenotypes, which is substantially inversely correlated with tumor heterogeneity [44]. Targeting DNA repair processes may influence the adaptive immune system by leading to an increased number of mutations, and subsequently increased burden of neoantigens, which in turn increases tumor heterogeneity, resulting in a higher probability of recognition by the immune system, and this has the potential to be exploited in therapeutic approaches [45]. Pan-cancer analysis suggested that increasing mutation load is linearly correlated with increasing immune activity in the tumor microenvironment of a tumor and is likely to influence immune recognition [46]. Therefore, FA pathway genes were found to be potential therapeutic targets for breast cancer and could be combined with immunotherapiy. In addition, the mRNA expression levels of FA pathway genes were also highly correlated with various immune cell infiltrations. These findings imply that FA pathway genes are not only prognostic indicators but also reflect the "immune-hot" status in breast cancer. DNA repair can also influence how the innate immune system initially responds to a tumor and recruits the adaptive immune system to the malignancy site [47]. Alterations in DNA repair can influence how the adaptive, innate, or both parts of the immune system respond to the underlying malignancy. However, further studies are required to verify the potential role of FA pathway genes in breast cancer as predictive biomarkers of immunotherapeutic responses. 
This study has some limitations. Analysis on the transcriptional level can reflect some immune status aspects, but not wholesome changes. Independent cohort and in vitro or in vivo studies should be performed to validate our results.

In summary, there is a significant correlation between the mRNA expression levels of FA pathway genes and tumor prognosis as well as the cancer immune infiltration. This implies that the genes may mediate tumor progression and exert immunotherapeutic effects in breast cancer. Therefore, elucidation of how these genes are regulated during tumor progression may highlight their potential prognostic and therapeutic role in breast cancer.

\section{Conclusion}

This study elucidates on the expression, mutations and prognostic values of FA pathway genes in breast cancer. Analysis of the relationship between FA pathway gene expression and clinicopathological characteristics in breast cancer indicated that FA pathway genes could be promising prognostic biomarkers in patients with breast cancer, and may be novel targets for breast cancer therapy. More studies are needed to explore the exact mechanisms and therapeutic roles of FA pathway genes in breast cancer. It is possible that the FA pathway genes will be effective prognostic markers of breast cancer in future.

\section{Abbreviations}

ER: oestrogen receptor; PR: progesterone receptor; HER2: human epidermal growth factor receptor 2; FA: Fanconi anemia; ICL: interstrand cross-links; TCGA: The Cancer Genome Atlas; GDC: Genomic Data Commons; GTEx: Genotype-Tissue Expression; GO: Gene Ontology; KEGG: Kyoto Encyclopedia of Genes and Genomes; RFS: recurrent free survival; OS: overall survival; DMFS: distant metastasis free survival; PPS: post progression survival; BP: biological process; CC: cellular component; MF: molecular function; VAFs: variant allele frequencies; HR: homologous recombination.

\section{Declarations}

\section{Ethics approval and consent to participate}

Not applicable.

\section{Consent for publication}

Not applicable.

\section{Availability of data and materials}

All data generated or analysed during this study are included in this published article. 


\section{Competing interests}

The authors declare that they have no competing interests.

\section{Funding}

This study was supported by the National Natural Science Foundation of China (No. 81960840; No. 81603575) to Mingfen Li, and Natural Science Foundation of Guangxi Zhuang Autonomous Region (No. 2018GXNSFBA281092) to Mingfen Li.

\section{Authors' contributions}

$\mathrm{HL}, \mathrm{YX}, \mathrm{AP}, \mathrm{LD}$ and $\mathrm{ML}$ contributed to the study concept and design of this study. YX, WW, LY and YK contributed to the acquisition, analysis, interpretation of data. $\mathrm{HL}$ and $\mathrm{YX}$ contributed to the drafting of the manuscript. ML contributed to the review and the revision of the manuscript. All authors read and approved the final manuscript.

\section{Acknowledgements}

Not applicable.

\section{References}

1. Siegel RL, Miller KD, Jemal A. Cancer statistics, 2020. CA Cancer J Clin. 2020;70:7-30.

2. Marcotte R, Sayad A, Brown KR, Sanchez-Garcia F, Reimand J, Haider M, et al. Functional Genomic Landscape of Human Breast Cancer Drivers, Vulnerabilities, and Resistance. Cell. 2016;164:293-309.

3. Coughlin SS. Epidemiology of Breast Cancer in Women. Adv Exp Med Biol. 2019;1152:9-29.

4. Auerbach AD. Fanconi anemia and its diagnosis. Mutat Res. 2009;668:4-10.

5. Rosenberg PS, Tamary H, Alter BP. How high are carrier frequencies of rare recessive syndromes? Contemporary estimates for Fanconi Anemia in the United States and Israel. Am J Med Genet A. 2011;155A:1877-83.

6. Degan P, Cappelli E, Regis S, Ravera S. New Insights and Perspectives in Fanconi Anemia Research. Trends Mol Med. 2019;25:167-70.

7. Kottemann MC, Smogorzewska A. Fanconi anaemia and the repair of Watson and Crick DNA crosslinks. Nature. 2013;493:356-63.

8. Nalepa G, Clapp DW. Fanconi anaemia and cancer: an intricate relationship. Nat Rev Cancer. 2018;18:168-85.

9. Kumar A, Coleman I, Morrissey C, Zhang X, True LD, Gulati R, et al. Substantial interindividual and limited intraindividual genomic diversity among tumors from men with metastatic prostate cancer. Nat Med. 2016;22:369-78. 
10. Seguí N, Mina LB, Lázaro C, Sanz-Pamplona R, Pons T, Navarro M, et al. Germline Mutations in FAN1 Cause Hereditary Colorectal Cancer by Impairing DNA Repair. Gastroenterology. 2015;149:563-6.

11. Ferroudj S, Yildiz G, Bouras M, Iscan E, Ekin U, Ozturk M. Role of Fanconi anemia/BRCA pathway genes in hepatocellular carcinoma chemoresistance. Hepatol Res. 2016;46:1264-74.

12. Roh YG, Mun JY, Kim SK, Park W, Jeong MS, Kim TN, et al. Fanconi Anemia Pathway Activation by FOXM1 Is Critical to Bladder Cancer Recurrence and Anticancer Drug Resistance. Cancers (Basel). $2020 ; 12$.

13. Lin $S$, Yu L, Song $X, B i$ J, Jiang $L$, Wang $Y$, et al. Intrinsic adriamycin resistance in p53-mutated breast cancer is related to the miR-30c/FANCF/REV1-mediated DNA damage response. Cell Death Dis. 2019;10:666.

14. Feng L, Jin F. Expression and prognostic significance of Fanconi anemia group D2 protein and breast cancer type 1 susceptibility protein in familial and sporadic breast cancer. Oncol Lett. 2019;17:3687700 .

15. Rhodes DR, Yu J, Shanker K, Deshpande N, Varambally R, Ghosh D, et al. ONCOMINE: a cancer microarray database and integrated data-mining platform. Neoplasia. 2004;6:1-6.

16. Goldman MJ, Craft B, Hastie M, Repečka K, McDade F, Kamath A, et al. Visualizing and interpreting cancer genomics data via the Xena platform. Nat Biotechnol. 2020;38:675-8.

17. Chandrashekar DS, Bashel B, Balasubramanya S, Creighton CJ, Ponce-Rodriguez I, Chakravarthi B, et al. UALCAN: A Portal for Facilitating Tumor Subgroup Gene Expression and Survival Analyses. Neoplasia. 2017;19:649-58.

18. Györffy B, Lanczky A, Eklund AC, Denkert C, Budczies J, Li Q, et al. An online survival analysis tool to rapidly assess the effect of 22,277 genes on breast cancer prognosis using microarray data of 1,809 patients. Breast Cancer Res Treat. 2010;123:725-31.

19. Cerami E, Gao J, Dogrusoz U, Gross BE, Sumer SO, Aksoy BA, et al. The cBio cancer genomics portal: an open platform for exploring multidimensional cancer genomics data. Cancer Discov. 2012;2:4014.

20. Tang Z, Li C, Kang B, Gao G, Li C, Zhang Z. GEPIA: a web server for cancer and normal gene expression profiling and interactive analyses. Nucleic Acids Res. 2017;45:W98-98W102.

21. Warde-Farley D, Donaldson SL, Comes O, Zuberi K, Badrawi R, Chao P, et al. The GeneMANIA prediction server: biological network integration for gene prioritization and predicting gene function. Nucleic Acids Res. 2010;38:W214-20.

22. Huang da W, Sherman BT, Lempicki RA. Systematic and integrative analysis of large gene lists using DAVID bioinformatics resources. Nat Protoc. 2009;4:44-57.

23. Li T, Fan J, Wang B, Traugh N, Chen Q, Liu JS, et al. TIMER: A Web Server for Comprehensive Analysis of Tumor-Infiltrating Immune Cells. Cancer Res. 2017;77:e108-108e110.

24. Sundquist M, Brudin L, Tejler G. Improved survival in metastatic breast cancer 1985-2016. Breast. 2017;31:46-50. 
25. Lu X, Liu R, Wang M, Kumar AK, Pan F, He L, et al. MicroRNA-140 impedes DNA repair by targeting FEN1 and enhances chemotherapeutic response in breast cancer. Oncogene. 2020;39:234-47.

26. Wang S, Liu F, Zhu J, Chen P, Liu H, Liu Q, et al. DNA Repair Genes ERCC1 and BRCA1 Expression in Non-Small Cell Lung Cancer Chemotherapy Drug Resistance. Med Sci Monit. 2016;22:1999-2005.

27. Pitroda SP, Bao R, Andrade J, Weichselbaum RR, Connell PP. Low Recombination Proficiency Score (RPS) Predicts Heightened Sensitivity to DNA-Damaging Chemotherapy in Breast Cancer. Clin Cancer Res. 2017;23:4493-500.

28. Klinakis A, Karagiannis D, Rampias T. Targeting DNA repair in cancer: current state and novel approaches. Cell Mol Life Sci. 2020;77:677-703.

29. Rajendra E, Garaycoechea JI, Patel KJ, Passmore LA. Abundance of the Fanconi anaemia core complex is regulated by the RuvBL1 and RuvBL2 AAA+ ATPases. Nucleic Acids Res. 2014;42:1373648.

30. Johnston SR. Clinical efforts to combine endocrine agents with targeted therapies against epidermal growth factor receptor/human epidermal growth factor receptor 2 and mammalian target of rapamycin in breast cancer. Clin Cancer Res. 2006;12:1061s-1068s.

31. Bellazzo A, Sicari D, Valentino E, Del Sal G, Collavin L. Complexes formed by mutant p53 and their roles in breast cancer. Breast Cancer (Dove Med Press). 2018;10:101-12.

32. Kandoth C, McLellan MD, Vandin F, Ye K, Niu B, Lu C, et al. Mutational landscape and significance across 12 major cancer types. Nature. 2013;502:333-9.

33. Sakai W, Swisher EM, Karlan BY, Agarwal MK, Higgins J, Friedman C, et al. Secondary mutations as a mechanism of cisplatin resistance in BRCA2-mutated cancers. Nature. 2008;451:1116-20.

34. Lang GT, Jiang YZ, Shi JX, Yang F, Li XG, Pei YC, et al. Characterization of the genomic landscape and actionable mutations in Chinese breast cancers by clinical sequencing. Nat Commun. 2020;11:5679.

35. Fang CB, Wu HT, Zhang ML, Liu J, Zhang GJ. Fanconi Anemia Pathway: Mechanisms of Breast Cancer Predisposition Development and Potential Therapeutic Targets. Front Cell Dev Biol. 2020;8:160.

36. Wang H, Li S, Oaks J, Ren J, Li L, Wu X. The concerted roles of FANCM and Rad52 in the protection of common fragile sites. Nat Commun. 2018;9:2791.

37. Daza-Martin M, Starowicz K, Jamshad M, Tye S, Ronson GE, MacKay HL, et al. Isomerization of BRCA1-BARD1 promotes replication fork protection. Nature. 2019;571:521-7.

38. Wang W, Nag S, Zhang X, Wang MH, Wang H, Zhou J, et al. Ribosomal proteins and human diseases: pathogenesis, molecular mechanisms, and therapeutic implications. Med Res Rev. 2015;35:225-85.

39. Korsholm LM, Gál Z, Lin L, Quevedo O, Ahmad DA, Dulina E, et al. Double-strand breaks in ribosomal RNA genes activate a distinct signaling and chromatin response to facilitate nucleolar restructuring and repair. Nucleic Acids Res. 2019;47:8019-35. 
40. Ogawa LM, Baserga SJ. Crosstalk between the nucleolus and the DNA damage response. Mol Biosyst. 2017;13:443-55.

41. Sondalle SB, Longerich $S$, Ogawa LM, Sung P, Baserga SJ. Fanconi anemia protein FANCl functions in ribosome biogenesis. Proc Natl Acad Sci U S A. 2019;116:2561-70.

42. Deng L, Lu D, Bai Y, Wang Y, Bu H, Zheng H. Immune Profiles of Tumor Microenvironment and Clinical Prognosis among Women with Triple-Negative Breast Cancer. Cancer Epidemiol Biomarkers Prev. 2019;28:1977-85.

43. Bianchini G, Balko JM, Mayer IA, Sanders ME, Gianni L. Triple-negative breast cancer: challenges and opportunities of a heterogeneous disease. Nat Rev Clin Oncol. 2016;13:674-90.

44. Zhang C, Cheng W, Ren X, Wang Z, Liu X, Li G, et al. Tumor Purity as an Underlying Key Factor in Glioma. Clin Cancer Res. 2017;23:6279-91.

45. Germano G, Lamba S, Rospo G, Barault L, Magrì A, Maione F, et al. Inactivation of DNA repair triggers neoantigen generation and impairs tumour growth. Nature. 2017;552:116-20.

46. Rooney MS, Shukla SA, Wu CJ, Getz G, Hacohen N. Molecular and genetic properties of tumors associated with local immune cytolytic activity. Cell. 2015;160:48-61.

47. Ma J, Setton J, Lee NY, Riaz N, Powell SN. The therapeutic significance of mutational signatures from DNA repair deficiency in cancer. Nat Commun. 2018;9:3292.

\section{Tables}

Table 1 The association between FA pathway genes expression and breast cancer grade of patients 


\begin{tabular}{|c|c|c|c|c|}
\hline Gene & Grade & Cases & $\mathrm{HR}(95 \% \mathrm{Cl})$ & $p$-value \\
\hline \multirow[t]{3}{*}{ FANCA } & 1 & 345 & $1.62(0.95-2.77)$ & 0.073 \\
\hline & 2 & 901 & $1.41(1.11-1.79)$ & $0.0051^{\star *}$ \\
\hline & 3 & 903 & $1.04(0.84-1.29)$ & 0.72 \\
\hline \multirow[t]{3}{*}{ FANCB } & 1 & 108 & $1.13(0.39-3.22)$ & 0.82 \\
\hline & 2 & 227 & $1.17(0.71-1.95)$ & 0.54 \\
\hline & 3 & 444 & $0.9(0.66-1.22)$ & 0.49 \\
\hline \multirow[t]{3}{*}{ FANCC } & 1 & 345 & $1.16(0.69-1.95)$ & 0.58 \\
\hline & 2 & 901 & $0.93(0.73-1.19)$ & 0.56 \\
\hline & 3 & 903 & $0.94(0.75-1.17)$ & 0.57 \\
\hline \multirow[t]{3}{*}{ FANCE } & 1 & 345 & $1.32(0.78-2.23)$ & 0.3 \\
\hline & 2 & 901 & $1.3(1.02-1.65)$ & $0.035^{\star}$ \\
\hline & 3 & 903 & $0.98(0.79-1.22)$ & 0.84 \\
\hline \multirow[t]{3}{*}{ FANCF } & 1 & 345 & $0.73(0.43-1.22)$ & 0.23 \\
\hline & 2 & 901 & $0.75(0.59-0.96)$ & $0.021^{\star}$ \\
\hline & 3 & 903 & $0.93(0.75-1.16)$ & 0.52 \\
\hline \multirow[t]{3}{*}{ FANCG } & 1 & 345 & $1.66(0.97-2.82)$ & 0.059 \\
\hline & 2 & 901 & $1.19(0.93-1.51)$ & 0.16 \\
\hline & 3 & 903 & $1.19(0.96-1.48)$ & 0.11 \\
\hline \multirow[t]{3}{*}{ FANCL } & 1 & 345 & $1.2(0.71-2.03)$ & 0.49 \\
\hline & 2 & 901 & $1.35(1.06-1.72)$ & $0.013^{*}$ \\
\hline & 3 & 903 & $1.16(0.93-1.44)$ & 0.19 \\
\hline \multirow[t]{3}{*}{ FANCM } & 1 & 108 & $1.34(0.46-3.87)$ & 0.59 \\
\hline & 2 & 227 & $1.49(0.9-2.49)$ & 0.12 \\
\hline & 3 & 444 & $1.1(0.81-1.5)$ & 0.54 \\
\hline \multirow[t]{3}{*}{ UBE2T (FANCT) } & 1 & 108 & $1.33(0.46-3.85)$ & 0.59 \\
\hline & 2 & 227 & $1.23(0.74-2.04)$ & 0.43 \\
\hline & 3 & 444 & $0.83(0.61-1.14)$ & 0.24 \\
\hline SLX4 (FANCP) & 1 & 108 & $1.29(0.45-3.71)$ & 0.64 \\
\hline
\end{tabular}




\begin{tabular}{|c|c|c|c|c|}
\hline & 2 & 227 & $1.19(0.71-1.99)$ & 0.5 \\
\hline & 3 & 444 & $1.01(0.74-1.37)$ & 0.97 \\
\hline \multirow[t]{3}{*}{ FANCD2 } & 1 & 108 & $1.09(0.38-3.11)$ & 0.87 \\
\hline & 2 & 227 & $0.72(0.43-1.2)$ & 0.21 \\
\hline & 3 & 444 & $0.89(0.65-1.22)$ & 0.47 \\
\hline \multirow[t]{3}{*}{ FANCI } & 1 & 345 & $1.81(1.06-3.1)$ & $0.029 *$ \\
\hline & 2 & 901 & $1.72(1.35-2.2)$ & $1 e-05^{\star \star \star}$ \\
\hline & 3 & 903 & $1.31(1.05-1.62)$ & $0.016 *$ \\
\hline \multirow[t]{3}{*}{ FANCD1 } & 1 & 345 & $1.15(0.68-1.93)$ & 0.61 \\
\hline & 2 & 901 & $1.22(0.96-1.55)$ & 0.11 \\
\hline & 3 & 903 & $0.96(0.77-1.2)$ & 0.74 \\
\hline \multirow[t]{3}{*}{ BRIP1 (FANCJ) } & 1 & 345 & $0.94(0.33-2.69)$ & 0.91 \\
\hline & 2 & 901 & $1.16(0.7-1.92)$ & 0.57 \\
\hline & 3 & 903 & $0.72(0.53-0.99)$ & $0.041^{*}$ \\
\hline \multirow[t]{3}{*}{ PALB2 (FANCN) } & 1 & 345 & $1.21(0.72-2.03)$ & 0.47 \\
\hline & 2 & 901 & $0.78(0.61-0.99)$ & $0.041^{*}$ \\
\hline & 3 & 903 & $1.13(0.91-1.4)$ & 0.28 \\
\hline \multirow[t]{3}{*}{ RAD51C (FANCO) } & 1 & 345 & $0.95(0.57-1.59)$ & 0.84 \\
\hline & 2 & 901 & $1.04(0.82-1.32)$ & 0.74 \\
\hline & 3 & 903 & $0.8(0.64-0.99)$ & $0.042^{*}$ \\
\hline \multirow[t]{3}{*}{ BRCC5 (FANCR) } & 1 & 345 & $1.1(0.65-1.84)$ & 0.72 \\
\hline & 2 & 901 & $1.36(1.07-1.73)$ & $0.012^{*}$ \\
\hline & 3 & 903 & $1.1(0.89-1.37)$ & 0.37 \\
\hline \multirow[t]{3}{*}{ BRCA1 (FANCS) } & 1 & 345 & $1.46(0.86-2.47)$ & 0.16 \\
\hline & 2 & 901 & $1.21(0.95-1.54)$ & 0.11 \\
\hline & 3 & 903 & $1.5(1.2-1.87)$ & $3 e-04^{\star \star \star}$ \\
\hline \multirow[t]{3}{*}{ XRCC2 (FANCU) } & 1 & 345 & $1.5(0.88-2.56)$ & 0.13 \\
\hline & 2 & 901 & $1.1(0.87-1.4)$ & 0.41 \\
\hline & 3 & 903 & $1.1(0.89-1.37)$ & 0.38 \\
\hline
\end{tabular}




\begin{tabular}{|lllll|} 
MAD2L2 (FANCV) & 1 & 108 & $0.78(0.27-2.26)$ & 0.65 \\
& 2 & 227 & $1.47(0.88-2.45)$ & 0.14 \\
& 3 & 444 & $0.85(0.62-1.16)$ & 0.3 \\
\hline RFWD3 (FANCW) & 1 & 345 & $1.67(0.97-2.85)$ & 0.06 \\
\hline & 2 & 901 & $1.5(1.18-1.91)$ & $0.00098^{\star \star *}$ \\
\hline ERCC4 (FANCQ) & 1 & 345 & $0.66(0.23-1.9)$ & 0.44 \\
& 2 & 901 & $0.85(0.51-1.42)$ & 0.54 \\
\hline & 3 & 903 & $1.05(0.77-1.43)$ & 0.77 \\
\hline
\end{tabular}

${ }^{\star} p<0.05, * \star p<0.01, * \star \star p<0.001$

Table 2 The association between FA pathway genes expression and ER status of patients with breast cancer 


\begin{tabular}{|c|c|c|c|c|}
\hline Gene & ER status & Cases & $\mathrm{HR}(95 \% \mathrm{Cl})$ & $p$-value \\
\hline \multirow[t]{2}{*}{ FANCA } & positive & 2061 & $1.41(1.19-1.66)$ & $4.3 e-05^{\star \star \star}$ \\
\hline & negative & 801 & $0.95(0.76-1.19)$ & 0.67 \\
\hline \multirow[t]{2}{*}{ FANCB } & positive & 762 & $1.61(1.2-2.15)$ & $0.0014^{\star \star}$ \\
\hline & negative & 347 & $0.82(0.59-1.14)$ & 0.23 \\
\hline \multirow[t]{2}{*}{ FANCC } & positive & 2061 & $1.08(0.92-1.28)$ & 0.33 \\
\hline & negative & 801 & $0.75(0.6-0.94)$ & $0.013^{*}$ \\
\hline \multirow[t]{2}{*}{ FANCE } & positive & 2061 & $1.19(1.01-1.4)$ & $0.04 *$ \\
\hline & negative & 801 & $1.02(0.81-1.27)$ & 0.88 \\
\hline \multirow[t]{2}{*}{ FANCF } & positive & 2061 & $0.94(0.8-1.11)$ & 0.45 \\
\hline & negative & 801 & $0.98(0.78-1.23)$ & 0.86 \\
\hline \multirow[t]{2}{*}{ FANCG } & positive & 2061 & $1.39(1.18-1.64)$ & $8.5 e-05^{\star \star \star}$ \\
\hline & negative & 801 & $1.02(0.81-1.28)$ & 0.86 \\
\hline \multirow[t]{2}{*}{ FANCL } & positive & 2061 & $1.18(1-1.39)$ & $0.049 *$ \\
\hline & negative & 801 & $1.16(0.93-1.46)$ & 0.19 \\
\hline \multirow[t]{2}{*}{ FANCM } & positive & 762 & $1.11(0.83-1.49)$ & 0.47 \\
\hline & negative & 347 & $0.89(0.64-1.24)$ & 0.5 \\
\hline \multirow[t]{2}{*}{ UBE2T (FANCT) } & positive & 762 & $1.89(1.4-2.55)$ & $2.4 \mathrm{e}-05^{\star \star \star}$ \\
\hline & negative & 347 & $0.89(0.64-1.24)$ & 0.5 \\
\hline \multirow[t]{2}{*}{ SLX4 (FANCP) } & positive & 762 & $1.24(0.93-1.66)$ & 0.14 \\
\hline & negative & 347 & $1.18(0.85-1.65)$ & 0.32 \\
\hline \multirow[t]{2}{*}{ FANCD2 } & positive & 762 & $1.07(0.8-1.43)$ & 0.66 \\
\hline & negative & 347 & $0.91(0.66-1.27)$ & 0.6 \\
\hline \multirow[t]{2}{*}{$\mathrm{FANCl}$} & positive & 2061 & $1.86(1.57-2.2)$ & $1.5 e-13^{\star \star \star}$ \\
\hline & negative & 801 & $1.12(0.89-1.4)$ & 0.32 \\
\hline \multirow[t]{2}{*}{ FANCD1 } & positive & 2061 & $1.16(0.98-1.36)$ & 0.081 \\
\hline & negative & 801 & $0.75(0.6-0.95)$ & $0.015^{\star}$ \\
\hline \multirow[t]{2}{*}{ BRIP1 (FANCJ) } & positive & 2061 & $1.67(1.24-2.24)$ & $0.00063^{\star \star \star}$ \\
\hline & negative & 801 & $0.91(0.65-1.26)$ & 0.56 \\
\hline
\end{tabular}




\begin{tabular}{|c|c|c|c|c|}
\hline \multirow[t]{2}{*}{ PALB2 (FANCN) } & positive & 2061 & $1.07(0.91-1.26)$ & 0.4 \\
\hline & negative & 801 & $1.04(0.83-1.3)$ & 0.73 \\
\hline \multirow[t]{2}{*}{ RAD51C (FANCO) } & positive & 2061 & $1.32(1.12-1.56)$ & $0.00083^{* \star *}$ \\
\hline & negative & 801 & $0.85(0.68-1.07)$ & 0.17 \\
\hline \multirow[t]{2}{*}{ BRCC5 (FANCR) } & positive & 2061 & $1.33(1.13-1.57)$ & $0.00066^{\star \star \star}$ \\
\hline & negative & 801 & $1.06(0.85-1.33)$ & 0.62 \\
\hline \multirow[t]{2}{*}{ BRCA1 (FANCS) } & positive & 2061 & $1.6(1.36-1.89)$ & $1.9 e-08 * \star \star$ \\
\hline & negative & 801 & $1.53(1.22-1.92)$ & 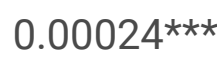 \\
\hline \multirow[t]{2}{*}{ XRCC2 (FANCU) } & positive & 2061 & $0.92(0.78-1.08)$ & 0.3 \\
\hline & negative & 801 & $0.93(0.74-1.16)$ & 0.51 \\
\hline \multirow[t]{2}{*}{ MAD2L2 (FANCV) } & positive & 762 & $1.02(0.77-1.37)$ & 0.88 \\
\hline & negative & 347 & $0.9(0.64-1.25)$ & 0.52 \\
\hline \multirow[t]{2}{*}{ RFWD3 (FANCW) } & positive & 2061 & $1.32(1.12-1.56)$ & $0.00082^{\star \star \star}$ \\
\hline & negative & 801 & $1.18(0.94-1.47)$ & 0.16 \\
\hline \multirow[t]{2}{*}{ ERCC4 (FANCQ) } & positive & 2061 & $1.21(0.91-1.62)$ & 0.2 \\
\hline & negative & 801 & $1.27(0.91-1.77)$ & 0.16 \\
\hline
\end{tabular}

${ }^{\star} p<0.05,{ }^{*} p<0.01, * \star * p<0.001$

Table 3 The association between FA pathway genes expression and PR status of patients with breast cancer 


\begin{tabular}{|c|c|c|c|c|}
\hline Gene & ER status & Cases & $\mathrm{HR}(95 \% \mathrm{Cl})$ & $p$-value \\
\hline \multirow[t]{2}{*}{ FANCA } & positive & 589 & $1.5(1.06-2.13)$ & $0.023^{*}$ \\
\hline & negative & 549 & $1.08(0.81-1.45)$ & 0.59 \\
\hline \multirow[t]{2}{*}{ FANCB } & positive & 489 & $1.42(0.97-2.08)$ & 0.069 \\
\hline & negative & 372 & $0.93(0.65-1.33)$ & 0.68 \\
\hline \multirow[t]{2}{*}{ FANCC } & positive & 589 & $1.41(0.99-2)$ & 0.054 \\
\hline & negative & 549 & $1.01(0.75-1.35)$ & 0.97 \\
\hline \multirow[t]{2}{*}{ FANCE } & positive & 589 & $1.12(0.79-1.58)$ & 0.53 \\
\hline & negative & 549 & $0.96(0.71-1.28)$ & 0.76 \\
\hline \multirow[t]{2}{*}{ FANCF } & positive & 589 & $0.85(0.6-1.21)$ & 0.36 \\
\hline & negative & 549 & $0.81(0.6-1.08)$ & 0.15 \\
\hline \multirow[t]{2}{*}{ FANCG } & positive & 589 & $1.78(1.24-2.54)$ & $0.0014^{\star \star}$ \\
\hline & negative & 549 & $1.19(0.89-1.59)$ & 0.24 \\
\hline \multirow[t]{2}{*}{ FANCL } & positive & 589 & $1.15(0.81-1.62)$ & 0.44 \\
\hline & negative & 549 & $0.95(0.71-1.28)$ & 0.76 \\
\hline \multirow[t]{2}{*}{ FANCM } & positive & 489 & $0.97(0.66-1.42)$ & 0.87 \\
\hline & negative & 372 & $1.03(0.72-1.47)$ & 0.86 \\
\hline \multirow[t]{2}{*}{ UBE2T (FANCT) } & positive & 489 & $1.71(1.16-2.52)$ & $0.0065^{\star \star}$ \\
\hline & negative & 372 & $1.05(0.74-1.51)$ & 0.77 \\
\hline \multirow[t]{2}{*}{ SLX4 (FANCP) } & positive & 489 & $1.13(0.77-1.65)$ & 0.52 \\
\hline & negative & 372 & $1.77(1.23-2.55)$ & $0.002^{\star *}$ \\
\hline \multirow[t]{2}{*}{ FANCD2 } & positive & 489 & $1.23(0.84-1.8)$ & 0.28 \\
\hline & negative & 372 & $1.28(0.89-1.82)$ & 0.18 \\
\hline \multirow[t]{2}{*}{$\mathrm{FANCl}$} & positive & 589 & $1.83(1.28-2.61)$ & $0.00074^{\star \star \star}$ \\
\hline & negative & 549 & $1.13(0.85-1.51)$ & 0.41 \\
\hline \multirow[t]{2}{*}{ FANCD1 } & positive & 589 & $1.41(1-2.01)$ & 0.051 \\
\hline & negative & 549 & $0.86(0.64-1.15)$ & 0.32 \\
\hline \multirow[t]{2}{*}{ BRIP1 (FANCJ) } & positive & 589 & $1.97(1.33-2.93)$ & $0.00055^{\star \star \star}$ \\
\hline & negative & 549 & $0.94(0.66-1.35)$ & 0.75 \\
\hline
\end{tabular}




\begin{tabular}{|lllll|}
\hline PALB2 (FANCN) & positive & 589 & $1.09(0.77-1.54)$ & 0.62 \\
& negative & 549 & $1.3(0.97-1.74)$ & 0.078 \\
\hline RAD51C (FANCO) & positive & 589 & $1.49(1.05-2.11)$ & $0.025^{\star}$ \\
& negative & 549 & $1.02(0.76-1.37)$ & 0.88 \\
\hline BRCC5 (FANCR) & positive & 589 & $1.44(1.01-2.04)$ & $0.041^{\star}$ \\
\hline BRCA1 (FANCS) & negative & 549 & $1.32(0.98-1.76)$ & 0.062 \\
\hline & negitive & 589 & $1.7(1.19-2.43)$ & $0.0032^{\star *}$ \\
\hline XRCC2 (FANCU) & positive & 589 & $0.98(0.69-1.39)$ & 0.89 \\
\hline & negative & 549 & $1.04(0.78-1.39)$ & 0.8 \\
\hline MAD2L2 (FANCV) & positive & 489 & $1.18(0.81-1.73)$ & 0.38 \\
\hline & negative & 372 & $1.14(0.8-1.63)$ & 0.47 \\
\hline RFWD3 (FANCW) & positive & 589 & $1.24(0.88-1.76)$ & 0.22 \\
\hline & negative & 549 & $1.32(0.99-1.77)$ & 0.06 \\
\hline ERCC4 (FANCQ) & positive & 589 & $1.02(0.7-1.49)$ & 0.9 \\
\hline & negative & 549 & $1.58(1.1-2.27)$ & $0.012^{\star}$ \\
\hline
\end{tabular}

${ }^{\star} p<0.05,{ }^{*} p<0.01,{ }^{* \star *} p<0.001$

Table 4 The association between FA pathway genes expression and HER2 status of patients with breast cancer 


\begin{tabular}{|c|c|c|c|c|}
\hline Gene & ER status & Cases & $\mathrm{HR}(95 \% \mathrm{Cl})$ & $p$-value \\
\hline \multirow[t]{2}{*}{ FANCA } & positive & 252 & $1.02(0.66-1.57)$ & 0.95 \\
\hline & negative & 800 & $1.35(1.04-1.75)$ & $0.025^{\star}$ \\
\hline \multirow[t]{2}{*}{ FANCB } & positive & 150 & $1.01(0.59-1.73)$ & 0.97 \\
\hline & negative & 635 & $1.41(1.05-1.9)$ & $0.024 *$ \\
\hline \multirow[t]{2}{*}{ FANCC } & positive & 252 & $0.83(0.54-1.29)$ & 0.41 \\
\hline & negative & 800 & $1.37(1.05-1.78)$ & $0.019 *$ \\
\hline \multirow[t]{2}{*}{ FANCE } & positive & 252 & $0.89(0.58-1.38)$ & 0.6 \\
\hline & negative & 800 & $1.12(0.86-1.45)$ & 0.41 \\
\hline \multirow[t]{2}{*}{ FANCF } & positive & 252 & $0.89(0.58-1.38)$ & 0.6 \\
\hline & negative & 800 & $0.76(0.58-0.99)$ & $0.04 *$ \\
\hline \multirow[t]{2}{*}{ FANCG } & positive & 252 & $1.42(0.91-2.19)$ & 0.12 \\
\hline & negative & 800 & $1.32(1.01-1.71)$ & $0.04 *$ \\
\hline \multirow[t]{2}{*}{ FANCL } & positive & 252 & $1.1(0.71-1.7)$ & 0.67 \\
\hline & negative & 800 & $1.06(0.81-1.37)$ & 0.67 \\
\hline \multirow[t]{2}{*}{ FANCM } & positive & 150 & $0.75(0.44-1.3)$ & 0.31 \\
\hline & negative & 635 & $1.09(0.81-1.46)$ & 0.58 \\
\hline \multirow[t]{2}{*}{ UBE2T (FANCT) } & positive & 150 & $0.61(0.35-1.06)$ & 0.078 \\
\hline & negative & 635 & $2.28(1.67-3.12)$ & $9.7 e-08^{\star \star *}$ \\
\hline \multirow[t]{2}{*}{ SLX4 (FANCP) } & positive & 150 & $1.45(0.84-2.51)$ & 0.18 \\
\hline & negative & 635 & $1.45(1.07-1.96)$ & $0.015^{\star}$ \\
\hline \multirow[t]{2}{*}{ FANCD2 } & positive & 150 & $0.51(0.29-0.9)$ & $0.019 *$ \\
\hline & negative & 635 & $1.39(1.03-1.87)$ & $0.032^{\star}$ \\
\hline \multirow[t]{2}{*}{$\mathrm{FANCl}$} & positive & 252 & $1.11(0.72-1.71)$ & 0.64 \\
\hline & negative & 800 & $1.79(1.37-2.34)$ & $1.5 e-05^{\star \star \star}$ \\
\hline \multirow[t]{2}{*}{ FANCD1 } & positive & 252 & $0.87(0.56-1.35)$ & 0.53 \\
\hline & negative & 800 & $1.22(0.94-1.59)$ & 0.13 \\
\hline \multirow[t]{2}{*}{ BRIP1 (FANCJ) } & positive & 252 & $0.61(0.35-1.05)$ & 0.072 \\
\hline & negative & 800 & $1.98(1.46-2.69)$ & $8.4 e-06^{\star \star \star}$ \\
\hline
\end{tabular}




\begin{tabular}{|c|c|c|c|c|}
\hline PALB2 (FANCN) & positive & 252 & $1.63(1.05-2.53)$ & $0.028^{*}$ \\
\hline & negative & 800 & $1.2(0.92-1.56)$ & 0.17 \\
\hline \multirow[t]{2}{*}{ RAD51C (FANCO) } & positive & 252 & $0.74(0.48-1.14)$ & 0.17 \\
\hline & negative & 800 & $1.44(1.1-1.87)$ & $0.0069 * *$ \\
\hline \multirow[t]{2}{*}{ BRCC5 (FANCR) } & positive & 252 & $1.41(0.91-2.19)$ & 0.12 \\
\hline & negative & 800 & $1.18(0.9-1.53)$ & 0.22 \\
\hline \multirow[t]{2}{*}{ BRCA1 (FANCS) } & positive & 252 & $1.13(0.73-1.75)$ & 0.58 \\
\hline & negative & 800 & $1.73(1.32-2.26)$ & $5.9 e-05^{\star \star \star}$ \\
\hline \multirow[t]{2}{*}{ XRCC2 (FANCU) } & positive & 252 & $1.02(0.66-1.57)$ & 0.95 \\
\hline & negative & 800 & $0.83(0.64-1.08)$ & 0.16 \\
\hline \multirow[t]{2}{*}{ MAD2L2 (FANCV) } & positive & 150 & $0.81(0.47-1.39)$ & 0.44 \\
\hline & negative & 635 & $1.16(0.86-1.56)$ & 0.34 \\
\hline \multirow[t]{2}{*}{ RFWD3 (FANCW) } & positive & 252 & $1.53(0.98-2.37)$ & 0.057 \\
\hline & negative & 800 & $1.21(0.93-1.57)$ & 0.16 \\
\hline \multirow[t]{2}{*}{ ERCC4 (FANCQ) } & positive & 252 & $0.81(0.47-1.4)$ & 0.46 \\
\hline & negative & 800 & $1.36(1.01-1.83)$ & $0.044^{\star}$ \\
\hline
\end{tabular}

${ }^{\star} p<0.05,{ }^{*} p<0.01,{ }^{* \star *} p<0.001$

Table 5 The association between FA pathway genes expression and TP53 status of patients with breast cancer 


\begin{tabular}{|c|c|c|c|c|}
\hline Gene & TP53 status & Cases & $\mathrm{HR}(95 \% \mathrm{Cl})$ & $p$-value \\
\hline \multirow[t]{2}{*}{ FANCA } & mutated & 188 & $0.87(0.54-1.41)$ & 0.58 \\
\hline & wild type & 273 & $1.84(1.19-2.83)$ & $0.0053^{* *}$ \\
\hline \multirow[t]{2}{*}{ FANCB } & mutated & 132 & $0.69(0.38-1.26)$ & 0.23 \\
\hline & wild type & 82 & $0.57(0.24-1.36)$ & 0.2 \\
\hline \multirow[t]{2}{*}{ FANCC } & mutated & 188 & $1.1(0.68-1.77)$ & 0.7 \\
\hline & wild type & 273 & $1.44(0.94-2.2)$ & 0.091 \\
\hline \multirow[t]{2}{*}{ FANCE } & mutated & 188 & $0.72(0.45-1.17)$ & 0.19 \\
\hline & wild type & 273 & $0.82(0.54-1.25)$ & 0.35 \\
\hline \multirow[t]{2}{*}{ FANCF } & mutated & 188 & $1.13(0.7-1.81)$ & 0.62 \\
\hline & wild type & 273 & $0.86(0.56-1.3)$ & 0.47 \\
\hline \multirow[t]{2}{*}{ FANCG } & mutated & 188 & $0.9(0.56-1.45)$ & 0.67 \\
\hline & wild type & 273 & $1.38(0.9-2.11)$ & 0.13 \\
\hline \multirow[t]{2}{*}{ FANCL } & mutated & 188 & $0.62(0.38-1)$ & $0.049 *$ \\
\hline & wild type & 273 & $1.09(0.72-1.66)$ & 0.68 \\
\hline \multirow[t]{2}{*}{ FANCM } & mutated & 132 & $0.8(0.45-1.45)$ & 0.47 \\
\hline & wild type & 82 & $0.93(0.4-2.15)$ & 0.86 \\
\hline \multirow[t]{2}{*}{ UBE2T (FANCT) } & mutated & 132 & $2.04(1.12-3.73)$ & $0.018^{\star}$ \\
\hline & wild type & 82 & $1.45(0.62-3.4)$ & 0.39 \\
\hline \multirow[t]{2}{*}{ SLX4 (FANCP) } & mutated & 132 & $0.86(0.48-1.55)$ & 0.61 \\
\hline & wild type & 82 & $1.4(0.6-3.27)$ & 0.44 \\
\hline \multirow[t]{2}{*}{ FANCD2 } & mutated & 132 & $0.54(0.3-0.99)$ & $0.043^{\star}$ \\
\hline & wild type & 82 & $1.58(0.67-3.7)$ & 0.29 \\
\hline \multirow[t]{2}{*}{$\mathrm{FANCl}$} & mutated & 188 & $0.88(0.55-1.41)$ & 0.6 \\
\hline & wild type & 273 & $1.75(1.14-2.69)$ & $0.01 *$ \\
\hline \multirow[t]{2}{*}{ FANCD1 } & mutated & 188 & $0.94(0.59-1.51)$ & 0.8 \\
\hline & wild type & 273 & $1.47(0.96-2.24)$ & 0.077 \\
\hline \multirow[t]{2}{*}{ BRIP1 (FANCJ) } & mutated & 188 & $0.92(0.51-1.65)$ & 0.78 \\
\hline & wild type & 273 & $1.74(0.74-4.08)$ & 0.2 \\
\hline
\end{tabular}




\begin{tabular}{|lllll|} 
PALB2 (FANCN) & mutated & 188 & $1.18(0.74-1.9)$ & 0.49 \\
& wild type & 273 & $0.87(0.57-1.32)$ & 0.5 \\
\hline RAD51C (FANCO) & mutated & 188 & $0.58(0.36-0.95)$ & $0.027^{\star}$ \\
& wild type & 273 & $1.1(0.72-1.68)$ & 0.64 \\
\hline BRCC5 (FANCR) & mutated & 188 & $0.65(0.4-1.04)$ & 0.073 \\
& wild type & 273 & $1.14(0.75-1.73)$ & 0.55 \\
\hline BRCA1 (FANCS) & mutated & 188 & $1.09(0.68-1.75)$ & 0.71 \\
& wild type & 273 & $1.69(1.1-2.59)$ & $0.016^{\star}$ \\
\hline XRCC2 (FANCU) & mutated & 188 & $1.32(0.82-2.12)$ & 0.26 \\
\hline & wild type & 273 & $1.12(0.73-1.7)$ & 0.6 \\
\hline MAD2L2 (FANCV) & mutated & 132 & $1.77(0.97-3.22)$ & 0.057 \\
\hline RFWD3 (FANCW) & mild type & 82 & $0.5(0.21-1.19)$ & 0.11 \\
\hline & mutated & 188 & $0.98(0.61-1.57)$ & 0.94 \\
\hline ERCC4 (FANCQ) & mutated & 188 & $1.17(0.65-2.1)$ & 0.61 \\
\hline & wild type & 273 & $1.2(0.52-2.78)$ & 0.67 \\
\hline
\end{tabular}

${ }^{\star} p<0.05,{ }^{* \star} p<0.01$

Figures 


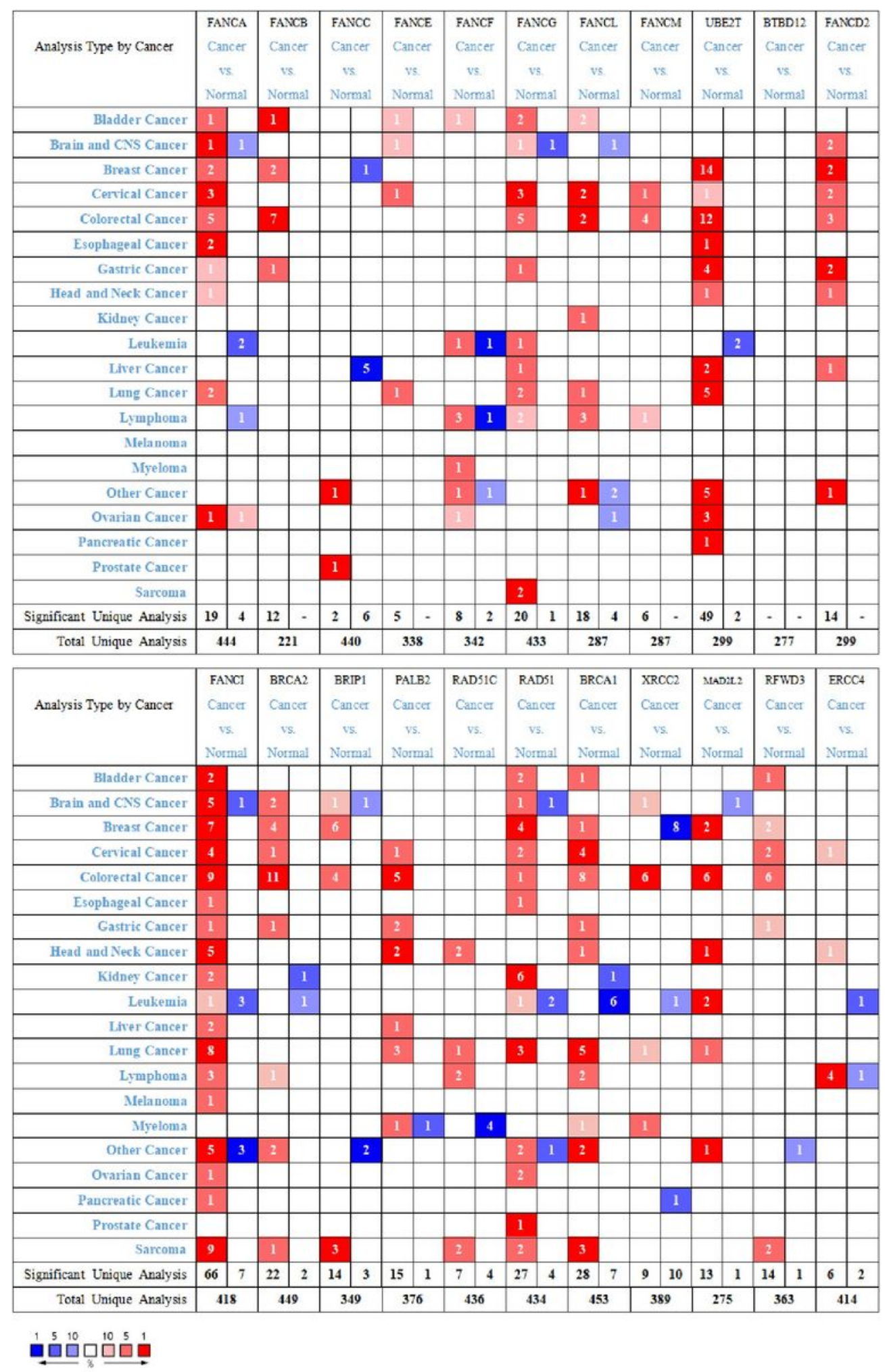

\section{Figure 1}

The transcription levels of FA pathway genes in different types of cancers using ONCOMINE database 


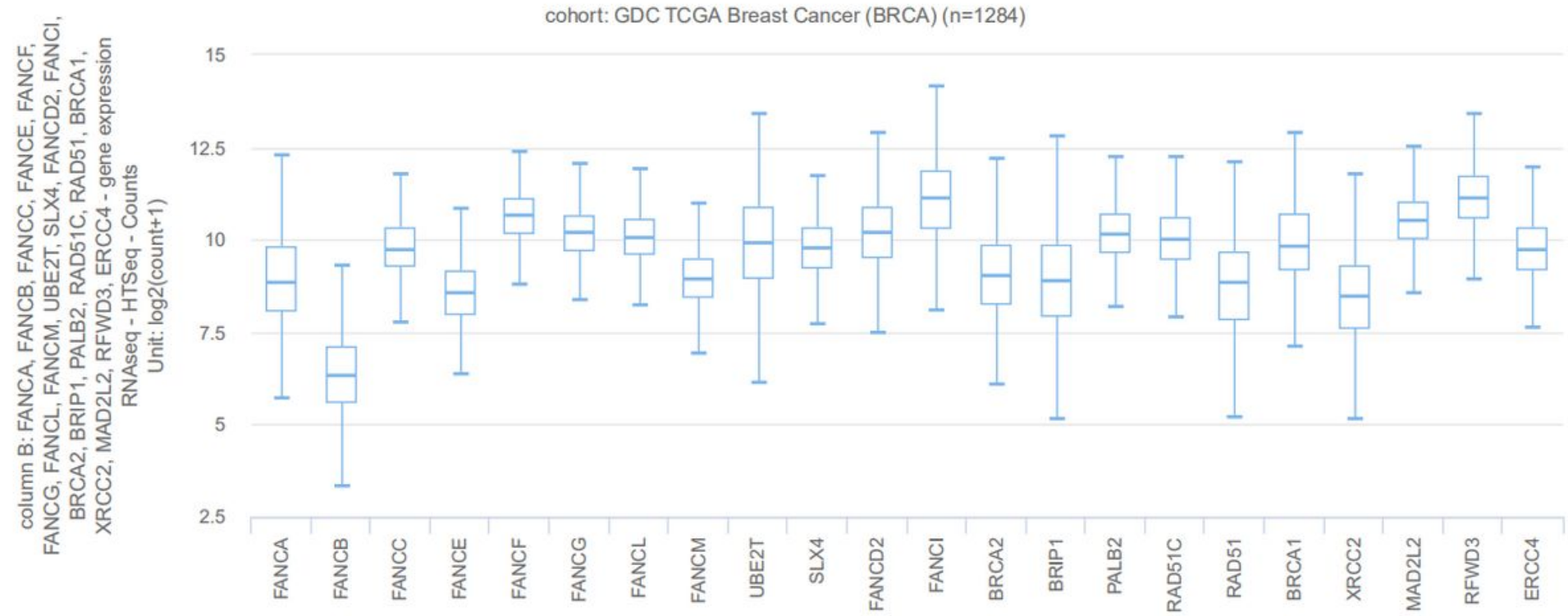

Figure 2

22 FA pathway genes expression differences in BRCA using UCSC Xena browser 

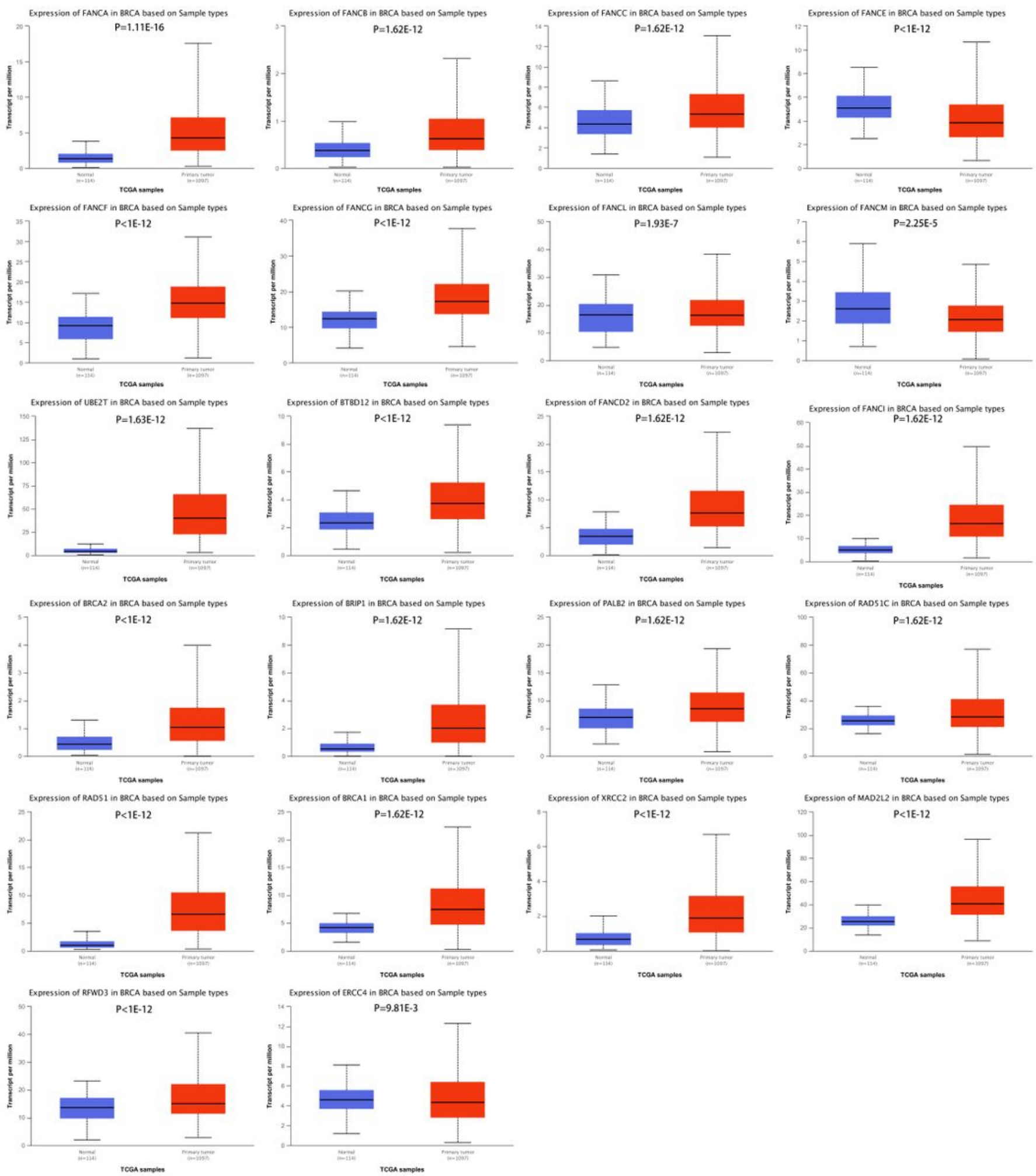

\section{Figure 3}

The mRNA expression of FA pathway genes varied in primary tumor and in corresponding normal tissues in patients with breast cancer using UALCAN database 

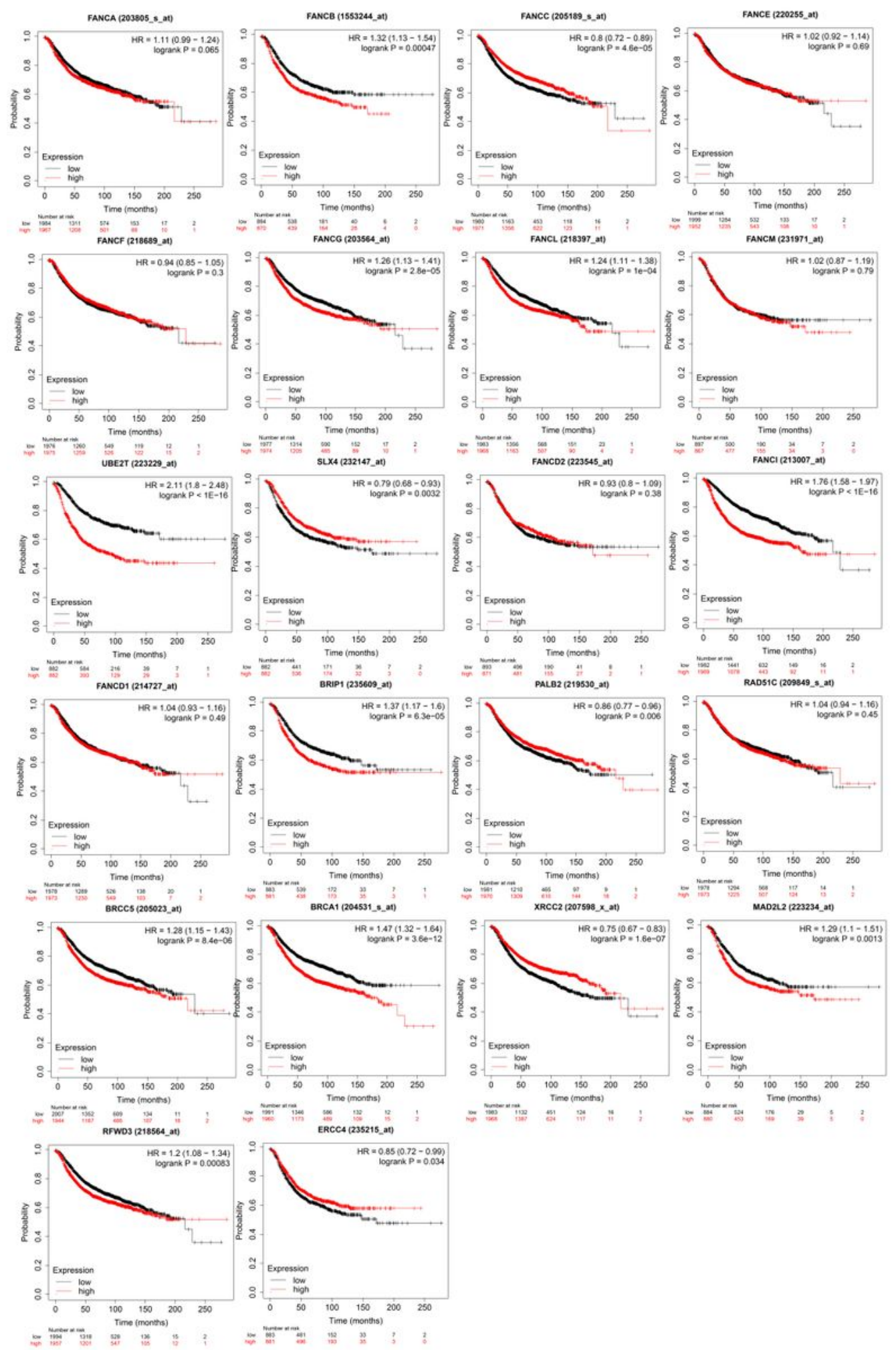

\section{Figure 4}

Survival analysis of FA pathway genes in patients with breast cancer using Kaplan-Meier plotter 


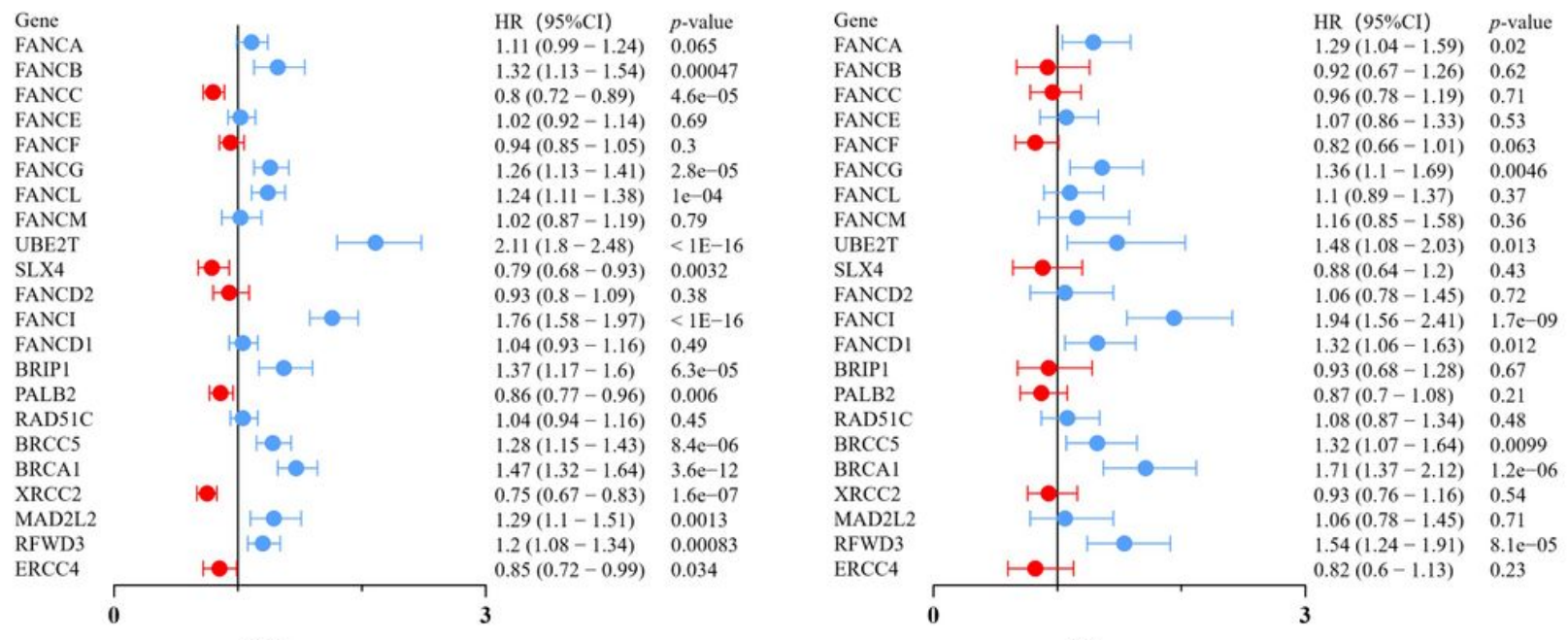

RFS

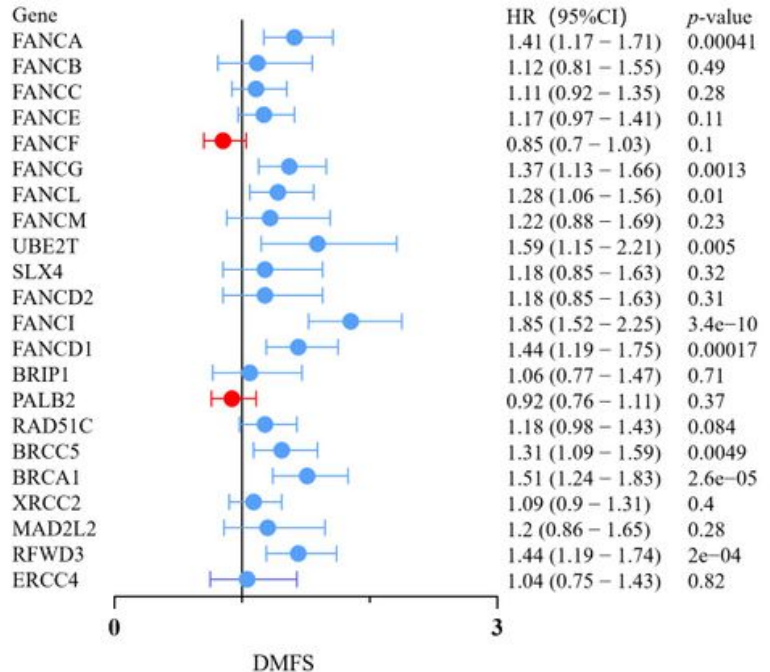

OS

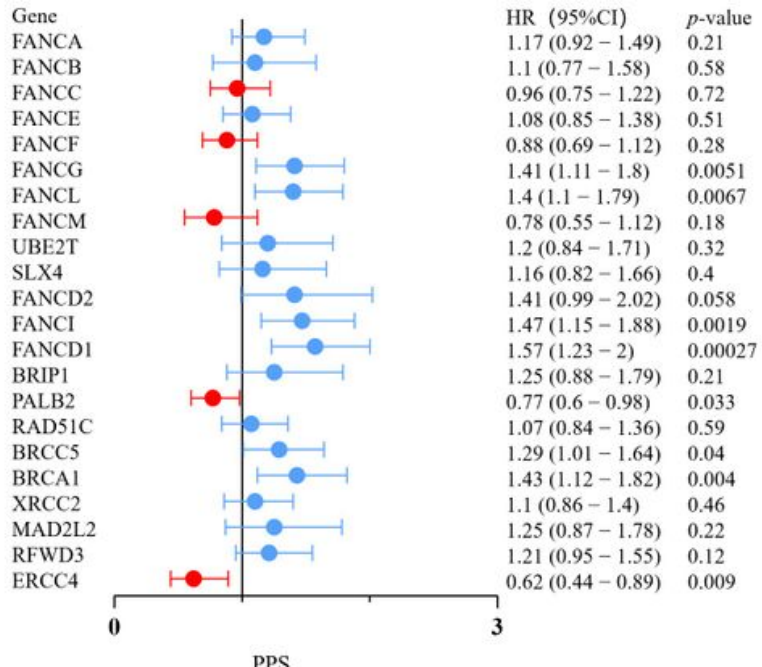

PPS

Figure 5

The correlation between expression of FA pathway genes and RFS, OS, DMFS, PPS of patients with breast cancer 
a

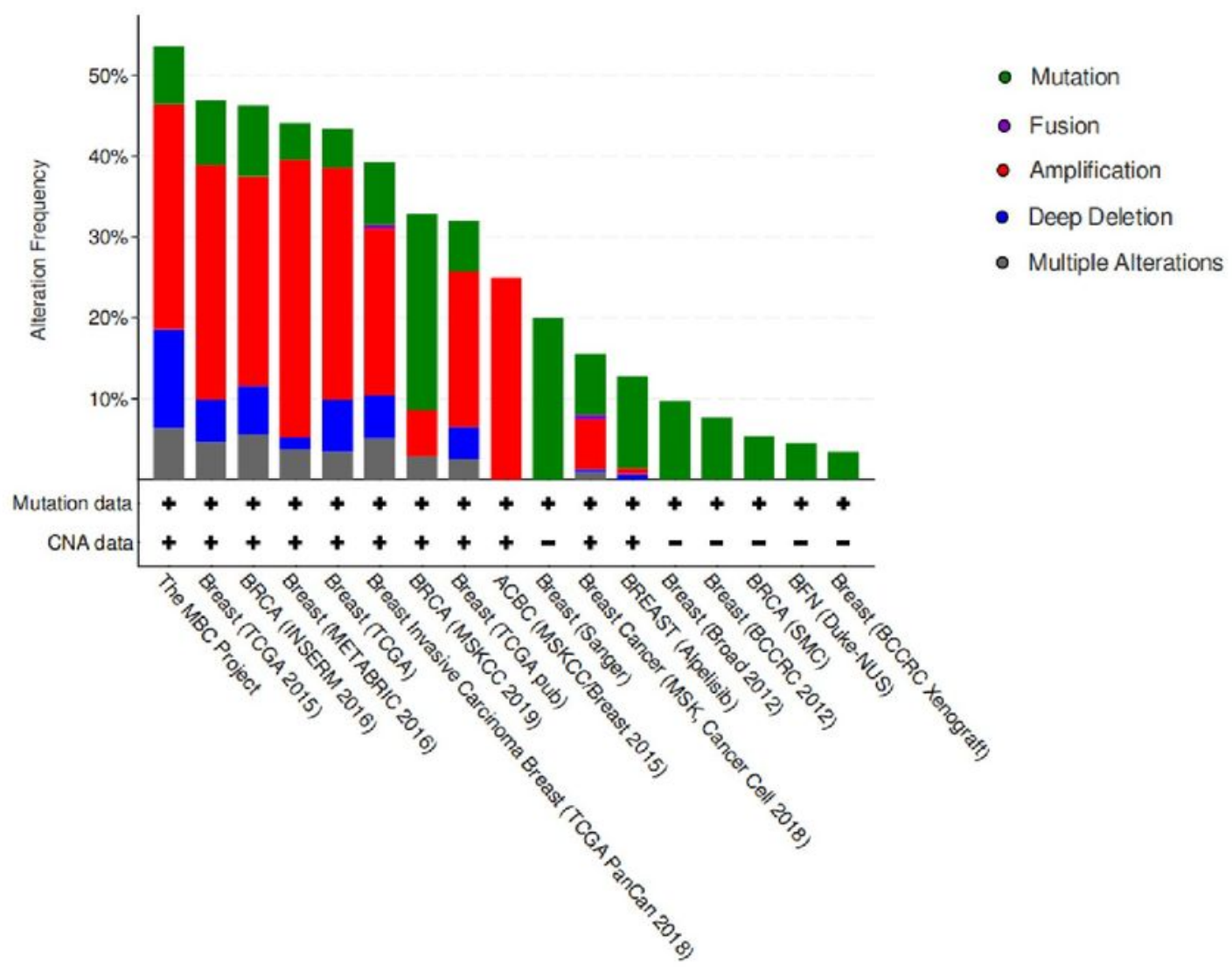

FANCA
FANCB
FANCC
FANCE
FANCF
FANCG
FANCL
FANCM
UBE2T
SLX4
FANCD2
FANC1
BRCA2
BRRP1
PALB2
RAD51C
RAD51
BRCA1
XRCC2
MAD2L2
RFWD3
ERCC4
Ganetic Nlaratio

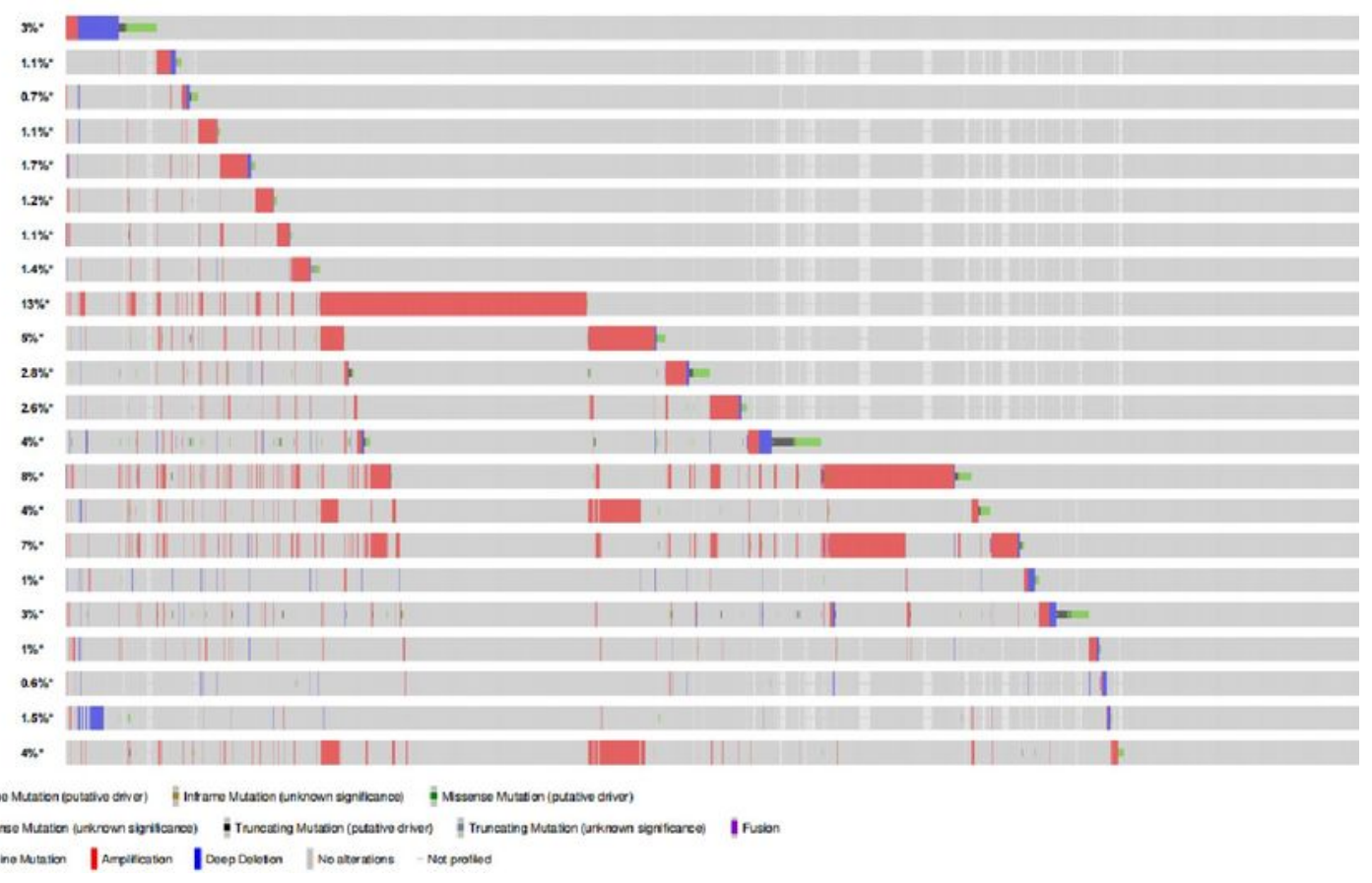

Figure 6

Alteration analysis was performed using cBioPortal database. a Alteration frequency of FA pathway genes in breast cancer. $b$ OncoPrint visual summary of FA pathway genes alterations in breast cancer 

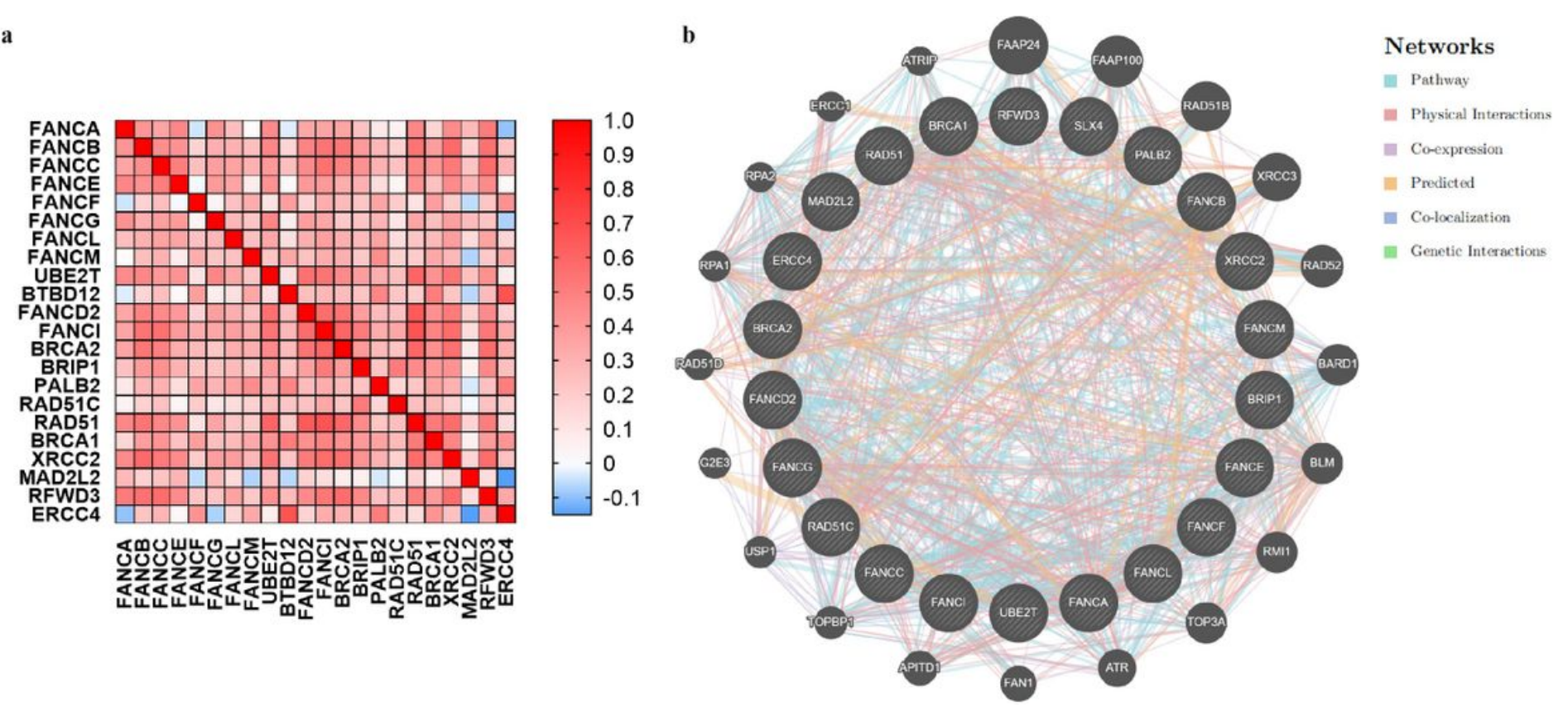

Figure 7

Interaction analysis of FA pathway genes. a Expression correlation heat map of differently expressed FA pathway genes in breast cancer using GEPIA database. b Gene-gene interaction network of FA pathway genes using GeneMANIA database 
a

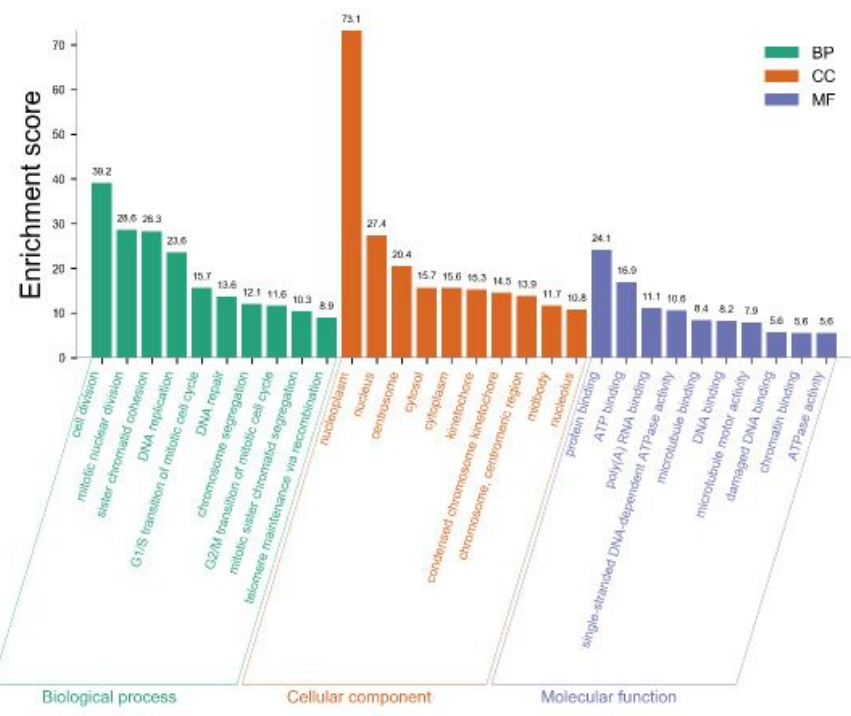

c

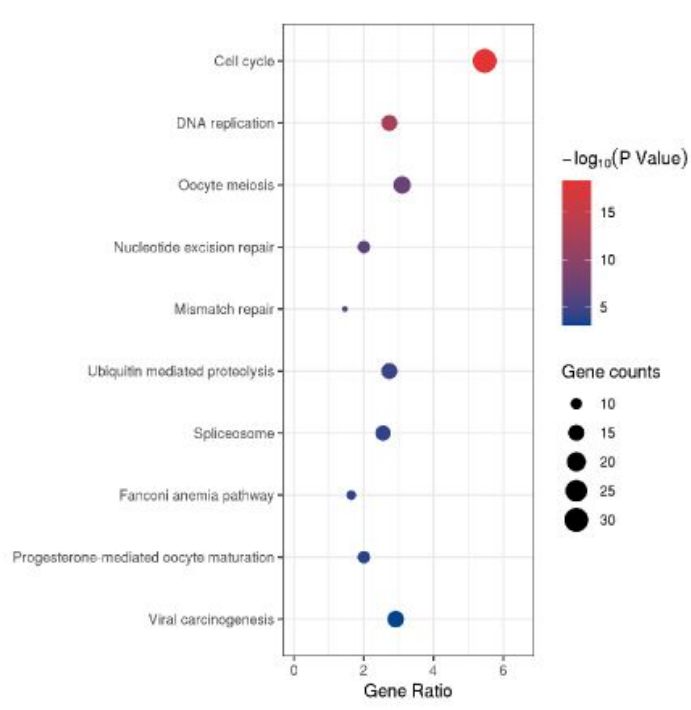

b
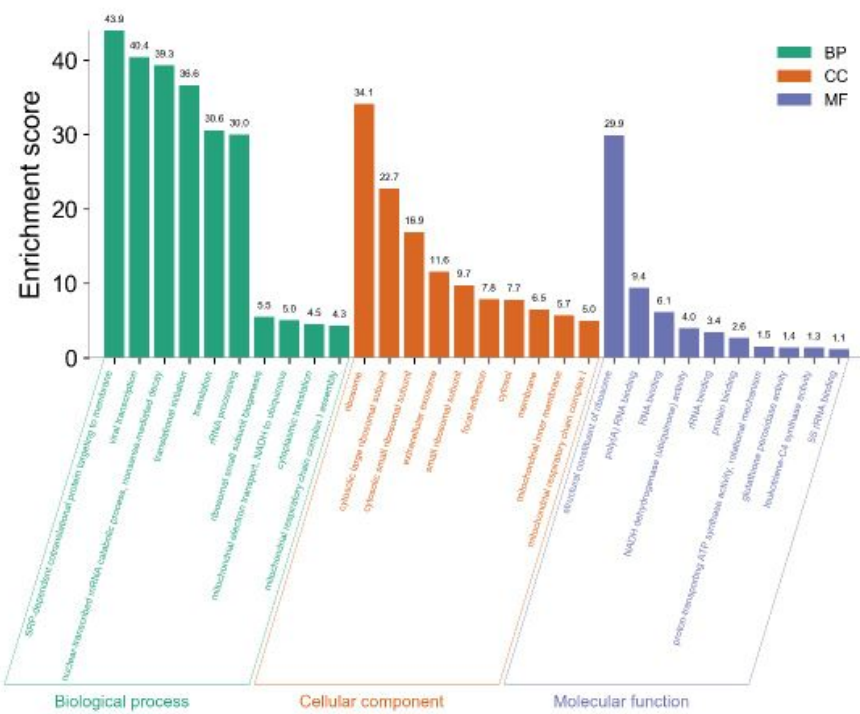

d

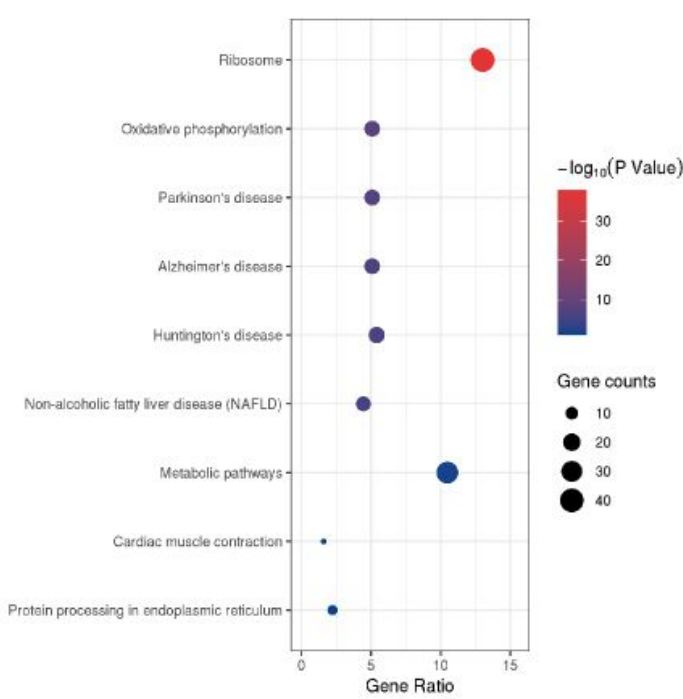

Figure 8

GO and KEGG pathway enrichment analysis of FA-related genes in breast cancer. a The most highly enriched GO items positively correlated with FA pathway genes. b The most highly enriched GO items negatively correlated with FA pathway genes. c The most highly enriched pathways positively correlated with FA pathway genes. $d$ The most highly enriched pathways negatively correlated with FA pathway genes 
iar. L =

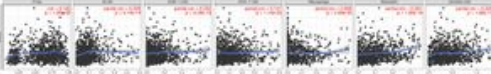
nis in

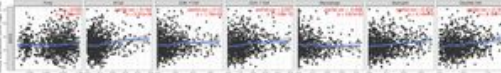

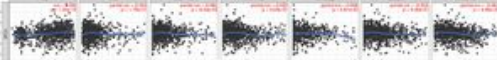
3.

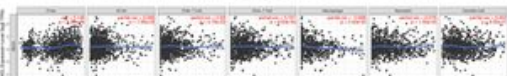

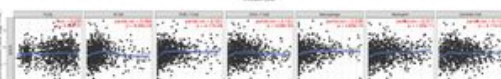

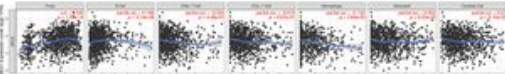

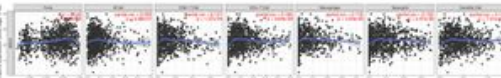

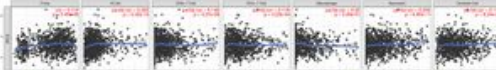

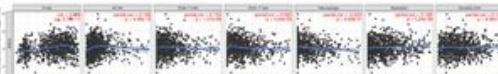

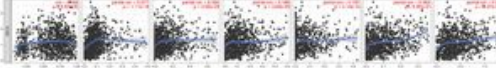

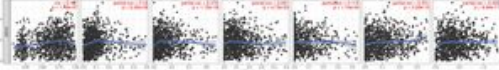

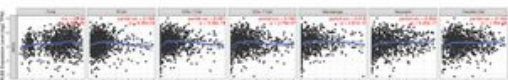

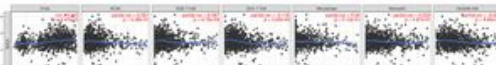
ond

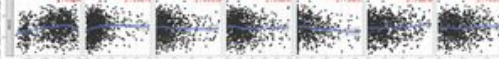
H. 1 N WN Uat V N : : Het L : He tor : 4. 5 N

\section{Figure 9}

The correlation between differently expressed FA pathway genes and immune cell infiltration in breast cancer using TIMER database 